\title{
Assessing the Validity of the Trauma Inventory for Partners of Sex Addicts (TIPSA)
}

Heidi A Vogeler

Brigham Young University

Follow this and additional works at: https://scholarsarchive.byu.edu/etd

Part of the Education Commons

\section{BYU ScholarsArchive Citation}

Vogeler, Heidi A, "Assessing the Validity of the Trauma Inventory for Partners of Sex Addicts (TIPSA)" (2020). Theses and Dissertations. 9046.

https://scholarsarchive.byu.edu/etd/9046

This Dissertation is brought to you for free and open access by BYU ScholarsArchive. It has been accepted for inclusion in Theses and Dissertations by an authorized administrator of BYU ScholarsArchive. For more information, please contact ellen_amatangelo@byu.edu. 
Assessing the Validity of the Trauma Inventory for Partners of Sex Addicts (TIPSA)

\author{
Heidi A. Vogeler
}

A dissertation submitted to the faculty of

Brigham Young University

in partial fulfillment of the requirements for the degree of

Doctor of Philosophy

\author{
Lane Fischer, Chair \\ Kristina S. Withers Hansen \\ Melissa Ann Heath \\ Aaron Paul Jackson \\ Department of Counseling Psychology and Special Education \\ Brigham Young University
}

Copyright (C) 2020 Heidi A. Vogeler

All Rights Reserved 


\begin{abstract}
Assessing the Validity of the Trauma Inventory for Partners of Sex Addicts (TIPSA)

Heidi A. Vogeler

Department of Counseling Psychology and Special Education, BYU

Doctor of Philosophy
\end{abstract}

The purpose of the current study was to provide both additional evidence of the psychometric properties of the Trauma Inventory for Partners of Sex Addicts (TIPSA) by examining reliability and validity coefficients, and to add to the empirical evidence for the application of betrayal trauma theory outside the context of complex and/or historical trauma. It was hypothesized that internal-consistency coefficients for the TIPSA would exceed 0.70; the TIPSA and the Posttraumatic Stress Disorder (PTSD) Checklist for DSM 5 (PCL-5) would be significantly positively correlated; the TIPSA and the Composite Codependency Scale (CCS) would not be significantly correlated; and that neither Adverse Childhood Experiences (ACE) nor Benevolent Childhood Experiences (BCE) scores would be significantly correlated with, or have a significant effect on TIPSA or PCL-5 scores. This study was conducted using anonymous survey data from 192 female participants who self-identified as partners of sex addicts. Participants completed the TIPSA, PCL-5, CCS, ACE, and BCE measures. All reliability estimates for the TIPSA were above 0.70 , as were all total-scale reliability estimates for the additional measures. Correlation between the TIPSA and PCL-5 produced a Pearson's $r$ of 0.851 $(p=5.541 \mathrm{E}-55)$, which indicated a large effect size. Correlations with additional measures produced statistically significant, yet small to weak, effect sizes (CCS: $r=0.292$; ACE: $r=$ -0.173 ; BCE: $r=0.244$ ). Based on study results, there appears to be sufficient evidence to establish convergent validity of the TIPSA as a measure of trauma symptoms. Moreover, statistical evidence indicates only a weak relationship between the TIPSA and the CCS, thus establishing divergent validity of the TIPSA. Finally, neither the BCE nor the ACE was strongly correlated with the TIPSA, which adds to the empirical evidence for utilizing betrayal trauma theory outside the context of complex trauma, and also serves to provide additional evidence for divergent validity of the TIPSA.

Keywords: statistical validity, posttraumatic stress disorder, codependency, sexual addiction 


\section{ACKNOWLEDGMENTS}

There are more people than I can count who deserve to be acknowledged for their help and support throughout the entire process of completing my second (second!) dissertation. I hope that I have expressed my gratitude in person to each of them and beg their forgiveness for not mentioning each by name. An extra debt of gratitude, however, is owed to a few specific individuals. First of all, my amazing committee. Aaron and Melissa, thank you for sticking with me through both dissertations, even though this study might not have been completely up your alley. And Kristina, thank for joining the team for round two. Your fresh eyes provided a muchneeded critical look at the structure and rationale for the study, and your attention to detail was most appreciated.

Next, I would be remiss if I did not thank Jennie Bingham. Jennie, thank you for your service on my prospectus committee, and for your willingness to serve from afar (though I am quite glad we didn't intrude on your fjording!). As the de facto content expert, your suggestions for additional literature and sources proved to be invaluable. They strengthened my dissertation in a way that was needful and unifying, and I would not have been able to produce the final product without you.

Last, but certainly not least, is Lane Fischer. Thank you for starting this whole mess, and for sticking with me through thick and thin. Your kindness and support have made all of this possible. How I lucked into having such an amazing chair, advisor, mentor, and friend I will never know. I do know that my gratitude is endless. And I do know that I will be forever grateful that our paths fortuitously crossed in Human Development, and this amazing adventure was the end result. Thank you. 


\section{TABLE OF CONTENTS}

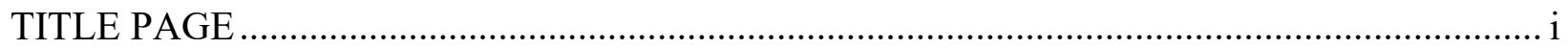

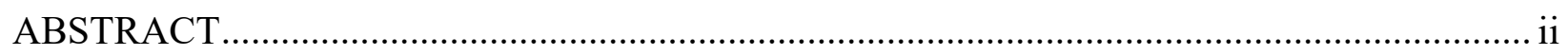

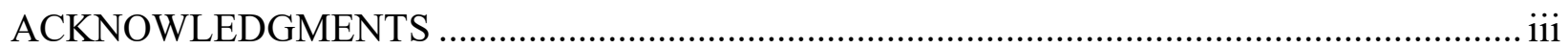

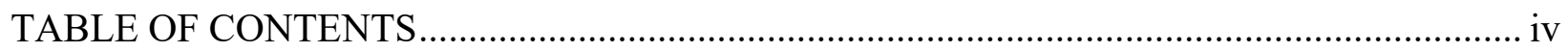

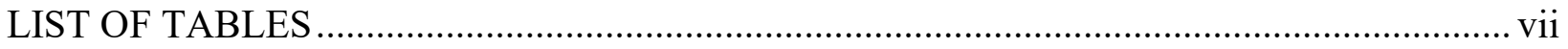

DESCRIPTION OF DISSERTATION STRUCTURE AND CONTENT ............................... viii

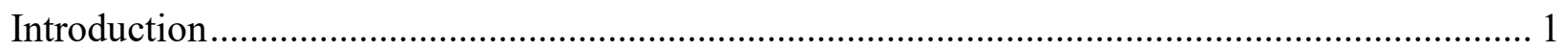

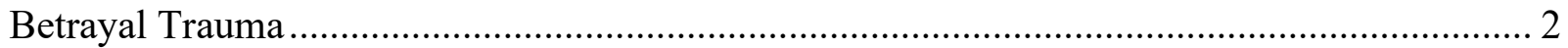

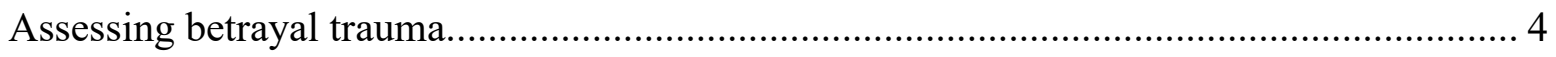

Trauma Inventory for Partners of Sex Addicts (TIPSA) .......................................... 5

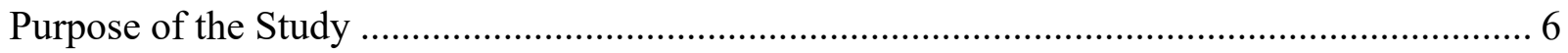

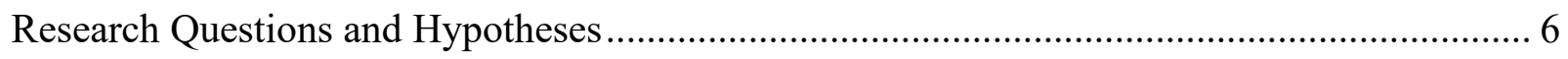

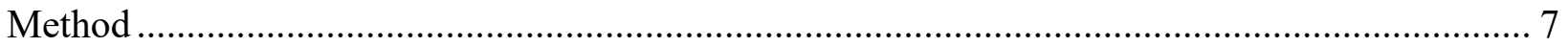

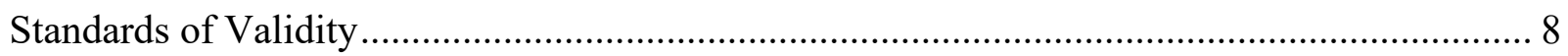

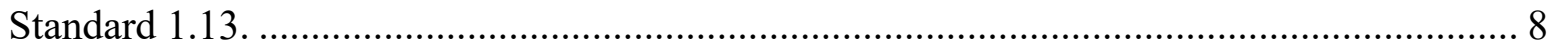

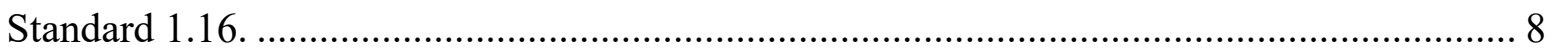

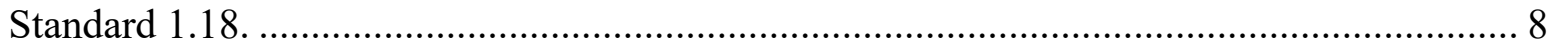

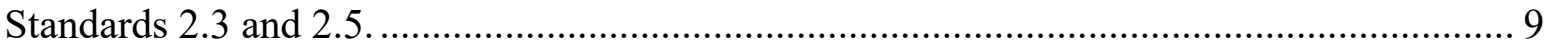

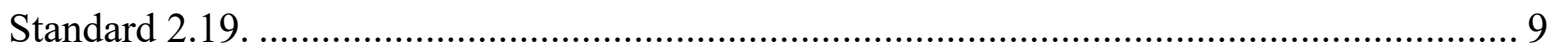

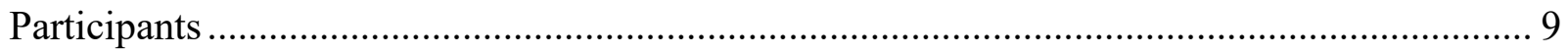

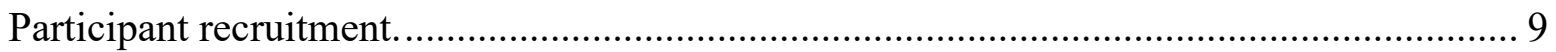

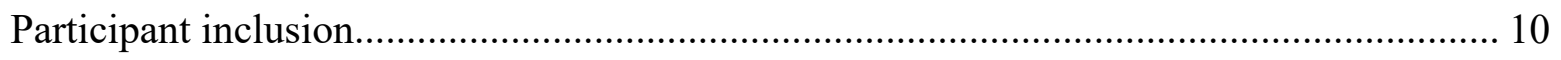




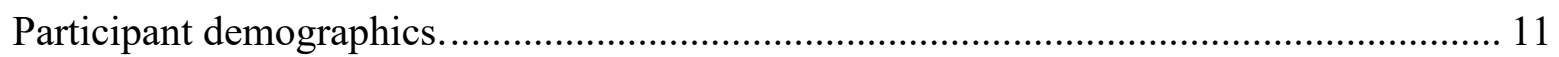

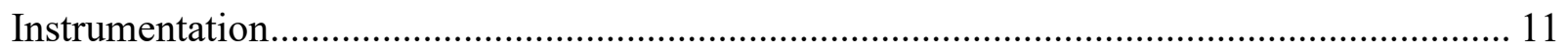

Trauma Inventory for Partners of Sex Addicts (TIPSA)..................................................... 11

Posttraumatic Stress Disorder (PTSD) Checklist for DSM-5 (PCL-5). ............................... 12

Adverse Childhood Experiences (ACE) Module..................................................................... 13

Benevolent Childhood Experiences (BCE) Questionnaire. ................................................. 14

Composite Codependency Scale (CCS)_..................................................................... 14

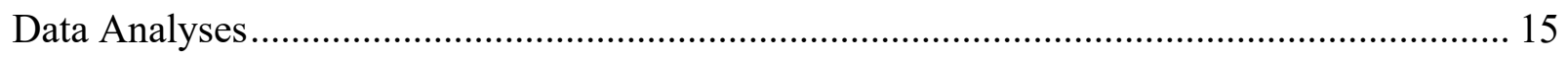

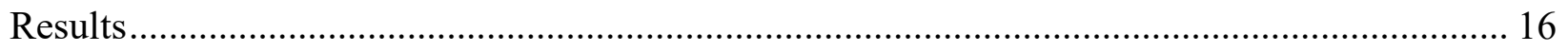

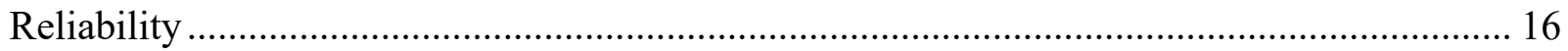

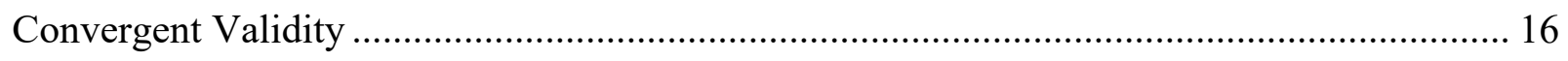

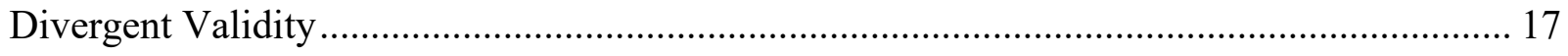

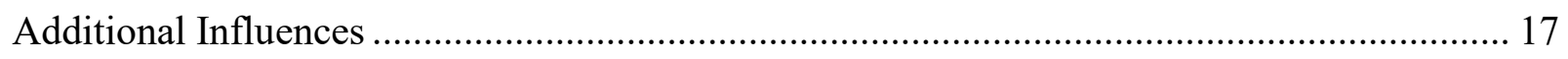

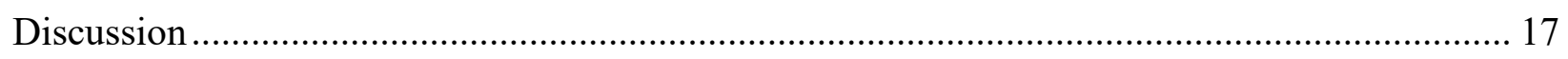

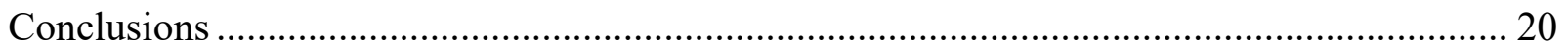

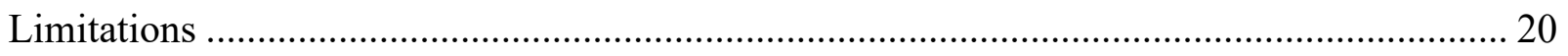

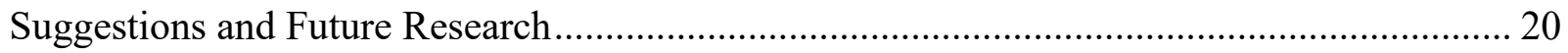

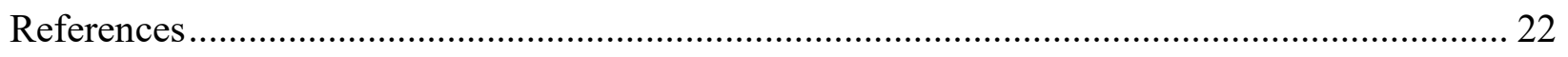

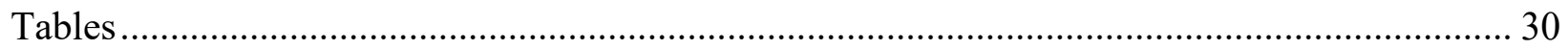

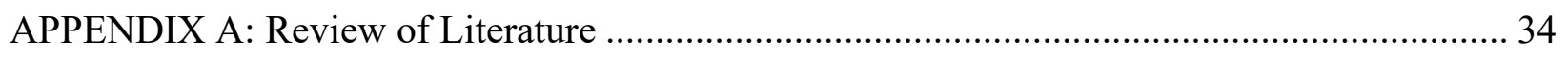

Defining Sexual Addiction ............................................................................................... 34

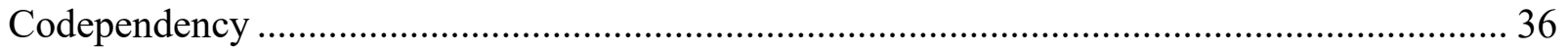

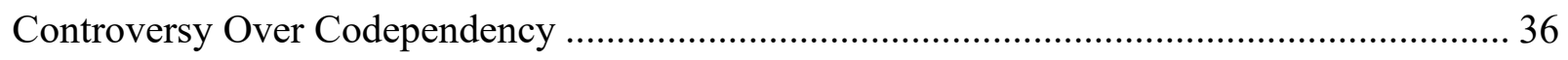


The Experiences of Partners of Sex Addicts .................................................................. 38

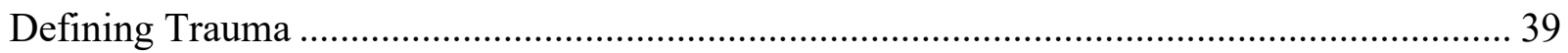

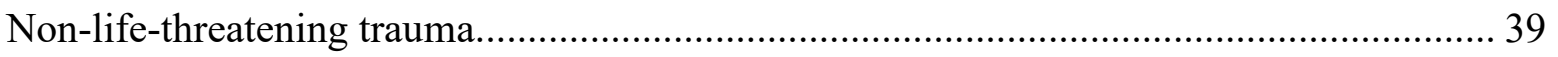

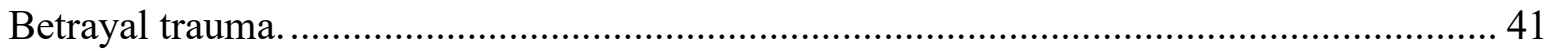

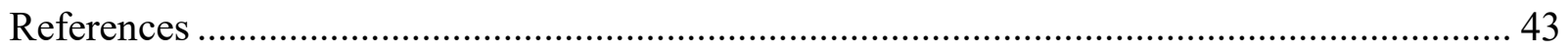

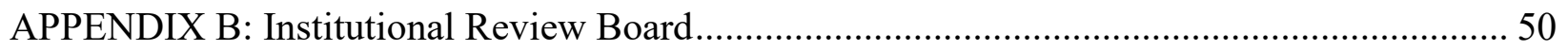

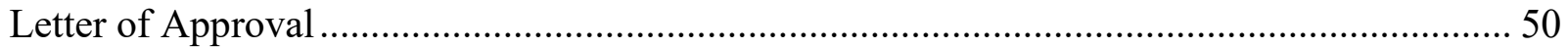

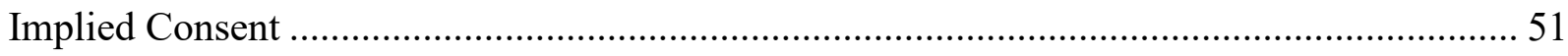

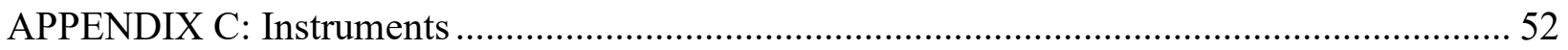

Trauma Inventory for Partners of Sex Addicts (TIPSA) ............................................... 52

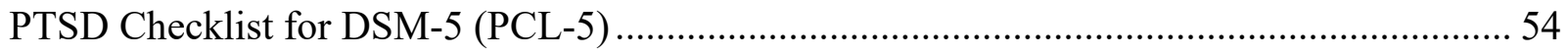

Adverse Childhood Experience (ACE) Module.............................................................. 55

Benevolent Childhood Experiences (BCE) Questionnaire ............................................... 56

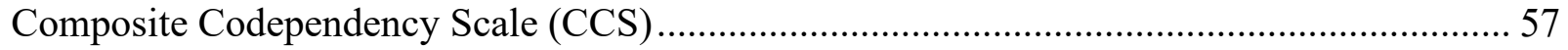




\section{LIST OF TABLES}

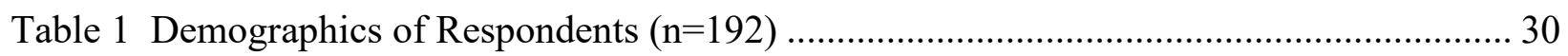

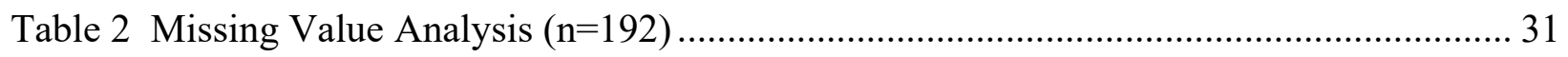

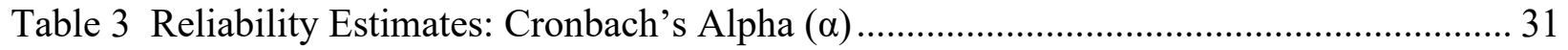

Table 4 Correlation Coefficients Between Subscales ........................................................... 32

Table 5 Zero-Order Correlations with TIPSA ................................................................ 32

Table 6 Regression Analyses for TIPSA: Block Entry and Stepwise ................................. 33

Table 7 Regression Analyses for PCL-5: Block Entry and Stepwise ..................................... 33 


\section{DESCRIPTION OF DISSERTATION STRUCTURE AND CONTENT}

This dissertation, Assessing the Validity of the Trauma Inventory for Partners of Sex Addicts (TIPSA), is written in a hybrid format. Utilizing this structure allows the author to bring together traditional dissertation requirements with a journal publication format. The preliminary pages of the dissertation reflect requirements for submission to the university. However, the actual dissertation report is presented as a journal article and conforms more closely to length and style requirements for submitting research reports to psychological journals.

While the introduction includes a brief review of relevant literature, a more comprehensive literature review is included in Appendix A. All of the analyses, results, discussion, and conclusions are included withing the body of the dissertation report. Documentation of Institutional Review Board (IRB) approval and implied consent are included in Appendix B. The study's instruments are provided in Appendix C. 


\section{Introduction}

Discovery or disclosure of an intimate partner's sexual addiction or compulsive sexual behaviors can be overwhelming, distressing, and even life-altering. In the literature regarding sexual addiction, discovery is defined as finding out about a sexual addiction, and disclosure is being told about a sexual addiction by the one experiencing the addiction (Carnes \& O'Connor, 2016; Minwalla, n.d.; Vogeler, 2017). In regards to sexual addiction itself, a possible diagnosis was considered for inclusion in the Diagnostic and Statistical Manual of Mental Disorders, 5th edition (DSM-5; American Psychiatric Association, 2013); however, it was classified as Hypersexual Disorder rather than an abuse/addiction disorder (Kafka, 2013; Kraus, Voon, \& Potenza, 2016). Ultimately, the disorder was not added to DSM-5. Rather, clinicians seem to prefer to attribute addictive/compulsive sexual behaviors to sexual disorders, mood disorders, or impulse disorders (Kraus et al., 2016). However, as sexual addiction is a term that is frequently used in the current literature, as well as in popular media, this term will be used throughout this paper (Steffens, 2005).

According to Carnes (2011), discovery of a partner's sex addiction is “a trauma that, for many partners, causes an acute stress reaction and possibly symptoms of post-traumatic stress disorder (PTSD)" (p. 3; see also Baird, 2011). Similarly, Schneider, Weiss, and Samenow (2012) found that over half of the partners of individuals with sex addictions (hereafter referred to as "sex addicts" per common usage in current literature) in their study considered themselves traumatized. Many who have discovered a partner's sexual addiction report experiencing feelings of anxiety, depression, anger, and rage, along with maladaptive behaviors such as obsessive thinking, isolating oneself from others, hypervigilance, and distraction (Carnes \& O'Connor, 2016; Steffens \& Rennie, 2006; Whisman \& Wagers, 2005). In other words, partners of sex 
addicts often report experiencing symptoms of trauma following discovery/disclosure of the behaviors/addiction (Schneider et al., 2012).

These symptoms are congruent with those required by the 5th edition of the Diagnostic and Statistical Manual of Mental Disorders (DSM-5) to give a diagnosis of PTSD (American Psychiatric Association, 2013). Yet, under the current definition, individuals reporting such symptoms would not meet the full diagnostic criteria for PTSD as the discovery and/or disclosure of a partner's sexual addiction is not considered a life-threatening event. According to DSM-5, traumatic events are ones where there is "exposure to actual or threatened death, serious injury, or sexual violence" (American Psychiatric Association, 2013, p. 271). Giordano et al. (2016) further explain that "individuals may directly experience or witness the trauma, hear of a loved one's traumatic event, or repeatedly hear of or see trauma (e.g., in one's occupation)" (p. 56). However, there are many who deem this definition of trauma to be too restrictive (Anders, Frazier, \& Frankfurt, 2011; Weathers \& Keane, 2007). Most notably, Briere and Scott (2015) state that earlier editions of the DSM included threats to psychological integrity as traumatic events; however, DSM-5 “does not consider events to be traumatic if they are merely highly upsetting but not life threatening... [therefore,] it undoubtedly underestimates the extent of actual trauma in the general population" (pp. 9-10). Accordingly, Briere and Scott (2015) define an event as traumatic if it is "extremely upsetting, at least temporarily overwhelms the individual's internal resources, and produces lasting psychological symptoms" (p. 10).

\section{Betrayal Trauma}

Following this vein of research, several authors have suggested that betrayal may be a core dimension of trauma, and that it may be possible to differentially predict symptoms of PTSD resulting from betrayal and from threat to life (Freyd \& Birrell, 2013; Gomez, Lewis, 
Noll, Smidt, \& Birrell, 2016; Kelley, Weathers, Mason, \& Pruneau, 2012; Platt \& Freyd, 2015).

The concept of betrayal trauma was first introduced by Freyd in 1991, and is generally defined as trauma that "occurs when the people or institutions we depend on for survival violate us in some way" (Freyd, 2003, para. 1). Originally Freyd used the term betrayal trauma primarily in connection with childhood traumas; specifically, childhood sexual abuse. But, in recent years the psychological definition of betrayal has been broadened in such a way that it can be described as "one party in a relationship [acting] in a way that favors his or her own interests at the expense of the other party's interests" (Fitness, 2001, p. 74). This has resulted in a broadening of the application of the term betrayal trauma as well. Now, rather than being used exclusively in the context of childhood sexual abuse, betrayal trauma is associated with instances of discrimination, workplace exploitation, institutional betrayal, and sexual infidelity (Freyd, 2013; Gomez et al., 2016; Smith \& Freyd, 2014).

Some suggest that adult reaction to betrayal trauma is actually part of a complex trauma history, rather than a response to a unique trauma (Cook et al., 2017). The term complex trauma generally describes "the experience of multiple, chronic and prolonged, developmentally adverse traumatic events, most often of an interpersonal nature" (van der Kolk, 2005, p. 402). Adults exposed to this type of chronic interpersonal trauma often exhibit psychological disturbances that are not reflected in the current definition of PTSD, with this exposure often resulting in a loss of capacities relating to self-regulation and the ability to relate to others in an interpersonal context (Cook et al., 2017; van der Kolk, Roth, Pelcovitz, Sunday, \& Spinazzola, 2005). However, whether related to a discrete trauma like discovery of an addiction, or a more complex trauma history, it appears there is cause to explore and acknowledge trauma resulting not only from 
events with a perceived life threat, but also from events involving betrayal of trusted relationships (Kelley et al., 2012).

Assessing betrayal trauma. When it comes to assessing trauma in the context of the betrayal of an intimate relationship, tradition may get in the way of accurate assessment (Vogeler, 2017). As partners of sex addicts seek counseling/therapy services, their presenting concerns may not fall within the current framework of PTSD, and therefore their symptoms may be attributed to comorbid conditions, suggesting that the symptoms occurred independently from PTSD symptoms (van der Kolk et al., 2005). Minwalla (2012) stated, "The traditional sex addiction field to this day still [focuses]...on diagnosing partners as 'co-addicts' and emphasizing treatment of codependency" (para. 9). Steffens and Rennie (2006) also suggested that the traditional addiction model "centers upon the (partner's) addictive or obsessive relationship with an addict and predisposition to the development of co-addiction due to the (partner's) traumatic and dysfunctional pasts” (p. 261).

While some professionals recognize the shock that individuals experience as a result of the disclosure/discovery of their partner's sex addiction, and some will even identify the symptoms of PTSD, many still endorse a traditional diagnosis of codependency which locates the source of pathology within the individual who has been harmed or betrayed (Gomez et al., 2016; Vogeler, Fischer, Sudweeks, \& Skinner, 2018). When this happens, clinicians unwittingly deny an individual's "accurate perceptions and feelings [of trauma]" (Schneider et al., 2012, p. 136). It has also been suggested that some individuals may become "disoriented and retraumatized by traditional treatment interventions that focus on educating and helping partners with their 'own disease'... while ignoring the treatment of trauma" (Minwalla, 2012, para. 1112). Additionally, van der Kolk et al. (2005) asserted that, "By relegating [symptoms] to 
seemingly unrelated "comorbid" conditions, fundamental trauma-related disturbances may be lost to scientific investigation, and clinicians may run the risk of applying treatment approaches that are not helpful" (p. 309). Thus, ensuring accurate assessment of betrayal trauma, specifically within the context of the discovery/disclosure of sex addition, is essential for the psychological well-being of partners of sex addicts. However, until recently, no valid or reliable instruments have been available for such purposes.

Trauma Inventory for Partners of Sex Addicts (TIPSA). The Trauma Inventory for Partners of Sex Addicts (TIPSA) was originally conceptualized by Skinner, Knowlton, and Manning to specifically assess for symptoms of PTSD in partners sex addicts (Skinner, K. B., personal communication, October 12, 2017). After its initial creation, Skinner modified the TIPSA to match the five diagnostic categories of PTSD as outlined in DSM-IV-TR (American Psychiatric Association, 2000; Vogeler et al., 2018). The result was "one of the first assessments, if not the very first, that looked at trauma that stemmed from a [partner's] sexual behaviors" (Skinner, 2015, para. 10).

The first psychometric studies of the TIPSA were completed in 2017, including both an item response theory (IRT) analysis of the individual items (Stokes, 2017), and a factor analysis comparing the latent factor structure of the TIPSA to the conceptual/criteria structure of PTSD (Vogeler et al., 2018). The results from these studies indicated positive psychometric properties of the TIPSA based on the fit statistics from the confirmatory factor analysis and suggested that additional studies be conducted to further substantiate the psychometric properties, specifically in regards to the instrument's validity and reliability. 


\section{Purpose of the Study}

The purpose of the current study was to further examine the psychometric properties of the TIPSA by estimating the reliability (internal consistency) and validity (convergent and divergent) of scores obtained from the revised version of the TIPSA. This study also sought to add to the empirical evidence for the application of betrayal trauma theory outside the context of complex and/or historical trauma, which is generally considered to begin with childhood trauma, by examining the relationship between scores from the TIPSA and scores from instruments that assess both adverse and benevolent childhood experiences.

\section{Research Questions and Hypotheses}

Below are the research questions and hypotheses upon which this study was based:

1. What are the estimated internal-consistency coefficients for the TIPSA?

It was hypothesized that internal-consistency coefficients for the TIPSA would exceed an acceptable cut-off of 0.70 .

2. What is the estimated convergent validity of the TIPSA with other validated measures of Posttraumatic Stress Disorder?

It was hypothesized that the TIPSA and the Posttraumatic Stress Disorder (PTSD) Checklist for DSM 5 (PCL-5) would be significantly positively correlated; thus, providing evidence of convergent validity in terms of assessing for symptoms of trauma.

3. What is the estimated divergent validity of the TIPSA with the other validated measures of Codependency? 
It was hypothesized that the TIPSA and the Composite Codependency Scale (CCS) would not be significantly correlated; thus, providing evidence of divergent validity in terms of trauma versus codependency.

4. What is the estimated effect of positive childhood experiences on TIPSA and PCL-5 scores?

It was hypothesized that Benevolent Childhood Experiences (BCE) scores would not be significantly correlated with, or have a significant effect on, TIPSA or PCL-5 scores.

5. What is the estimated effect of negative childhood experiences (complex trauma) on TIPSA and PCL-5 scores?

It was hypothesized that Adverse Childhood Experiences (ACE) scores would not be significantly correlated with, or have a significant effect on, TIPSA or PCL-5 scores.

\section{Method}

This study was conducted using anonymous survey data, collected through Qualtrics, an online survey platform. Questions included items from the Trauma Inventory for Partners of Sex Addicts (TIPSA), the PTSD Checklist for DSM-5 (PCL-5), the Adverse Childhood Experience (ACE) questionnaire, the Benevolent Childhood Experiences (BCE) questionnaire, and the Composite Codependency Scale (CCS). Each of these instruments is described in the measures section. In addition, demographic information and other descriptive data, such as experiences of blame and denial, was also collected. Approval to collect and use this data was obtained from the Brigham Young University Institutional Review Board (IRB) in March 2019 (see Appendix B). 


\section{Standards of Validity}

Validity evidence was provided in accordance with the Standards for Educational and Psychological Testing (American Educational Research Association [AERA], American Psychological Association [APA], National Council on Measurement in Education [NCME], \& Joint Committee on Standards for Educational and Psychological Testing (U.S.), 2014)

Standard 1.13. "If the rationale for a test score interpretation for a given use depends on premises about the relationships among test items or among parts of the test, evidence concerning the internal structure of the test should be provided" (AERA et al., 2014, pp. 26-27). Evidence for this standard was established in a previous study that examined the factor structure of the TIPSA in comparison to the criteria structure for diagnosing PTSD (Vogeler et al., 2018).

Standard 1.16. "When validity evidence includes empirical analyses of responses to test items together with data on other variables, the rationale for selecting the additional variable should be provided" (AERA et al., 2014, p. 27). Meeting the burden of evidence for this standard was the primary objective of this study. Multiple measures (as identified in the following section) were compared in order to identify the type and strength of relationships between the measures and the related constructs. Of particular interest were the dependence of the relationship between the TIPSA and PCL-5 in terms of the construct of trauma (convergent evidence), and the independence of the relationship between the TIPSA and the CCS in terms of the constructs of trauma and codependency (discriminant evidence). In addition, the relationship between other possible mediating variables (such as previous childhood experiences) were also explored.

Standard 1.18. "When it is asserted that a certain level of test performance predicts adequate or inadequate criterion performance, information about the levels of criterion 
performance associated with given levels of test scores should be provided" (AERA et al., 2014, p. 28). According to the explanatory guidelines for this standard, providing correlation coefficients alone is generally insufficient to describe the patterns of association; regression equations are often deemed more insightful in terms of describing relationships between test and other variables. Accordingly, both bivariate correlations and regression coefficients were calculated in order to provide evidence of both convergent and discriminant validity (AERA et al., 2014). These values, along with other statistical summaries, are reported in the results section.

Standards 2.3 and 2.5. "For each total score, sub-score, or combination of scores that is to be interpreted, estimates of relevant indices of reliability/precision should be reported...Reliability estimation procedures should be consistent with the structure of the test" (AERA et al., 2014, p. 43) In accordance with these two standards, estimates of the internal consistency (Cronbach's alpha) for the TIPSA were calculated and reported in the results section, along with estimates for the other measures. General convention describes alphas above 0.70 as acceptable.

Standard 2.19. "Each method of quantifying the reliability/precision of scores should be described clearly and expressed in terms of statistics appropriate to the method. The sampling procedures used...and the descriptive statistics on these samples...should be reported" (AERA et al., 2014, p. 47). Sampling procedures and descriptive statistics are provided in the methods section in order to meet this standard.

\section{Participants}

Participant recruitment. Participants for this study were recruited using an online, selfselection method. An article regarding Betrayal Trauma was written by Dr. Skinner (2015, Aug 
13) and published on PsychologyToday.com. The article included a link to a version of the TIPSA which had been updated based on previous studies (see Vogeler, et al., 2018). The link directed participants to a Qualtrics version of the questionnaire which had been approved for the current study. Interested individuals voluntarily followed the embedded link to participate in the study. All participants were required to provide consent for their responses to be used for research purposes prior to completing the questionnaire. The implied consent form is included in Appendix B.

Power analysis utilizing both published charts (Ellis, 2010) and G*Power 3.1 software (Faul, Erdfelder, Buchner, \& Lang, 2009), suggested that 193 participants were needed in order to detect bivariate correlations of at least $r=0.20$, with $\alpha=0.05$ and power $(1-\beta)=0.80$. Accordingly, in order to maximize the ability to identify significant correlations, data collection continued until Qualtrics showed that 258 responses had been obtained.

Participant inclusion. As previous studies regarding the TIPSA utilized all-female samples (see Stokes, 2017; Vogeler et al., 2018), the same condition was selected as an inclusion criterion for the current study. Of the original 258 identified cases, 228 (88.37\%) self-identified as female and were retained; the remaining 30 cases were excluded from the study. Another inclusion criterion was completion of the PCL-5 with no more than four missing items. This criterion was identified given the importance of the PCL-5 in completing the validation analyses that were central to this study. Based on this criterion, an additional 22 cases were excluded from the sample.

A third criterion was completion of all five TIPSA subscales with no more than two missing values per subscale. An examination of responses identified six cases that failed to meet this criterion and were excluded from the sample. The final inclusion criterion was completion of 
the CCS with no more than 4 missing items. This criterion was utilized given that the CCS was necessary for establishing discriminant validity. Eight cases failed to meet this criterion and were also excluded. The resultant final sample size was 192 unique cases. Power analysis suggested 193 cases as the optimal $\mathrm{n}$ for this study; thus, the sample size was deemed sufficient for the intended analyses.

Participant demographics. Of the 192 cases in the female-only sample, $79.2 \%$ reported being between the ages of 25 and 54, 64.1\% reported being currently married, $58.9 \%$ reported knowing about their partner's behaviors for at least two years, $80.7 \%$ reported having completed at least some education beyond high school, $83.3 \%$ identified as White, and $59.4 \%$ identified as Christian. A detailed demographic breakdown is included in Table 1.

\section{Instrumentation}

Several measures were utilized in order to establish convergent and divergent validity. Basic descriptions and psychometric properties of each measure are included below, and the instruments in their entirety are included in Appendix C.

Trauma Inventory for Partners of Sex Addicts (TIPSA). The current version of the TIPSA consists of 51 items which are designed to assess symptoms of posttraumatic stress in the context of the discovery and/or disclosure of an intimate partner's sexually addictive behavior. The underlying factor structure of the TIPSA mirrors that of the DSM-5 criteria for diagnosing PTSD, and each item is designed to elicit responses that correlate with these criteria (Vogeler et al., 2018). Nine items focus on Criterion A (exposure to threats of death, injury, sexual violence, or sexually transmitted disease); 10 on Criterion B (reexperiencing event); six items on Criterion C (avoidance of trauma-related stimuli); 13 on Criterion D (negative thoughts or feelings); and 13 on Criterion E (trauma-related emotional arousal). Rho estimates of reliability 
for each subscale range from 0.701 to 0.894 , with and overall score Rho estimate of 0.954 (Vogeler, 2017).

TIPSA items are endorsed on a 5-point Likert scale from 0 (never) to 4 (always), with intermediate categories of 1 (sometimes), 2 (about half the time), and 3 (most of the time). The highest-possible combined score on the TIPSA is 204 , with possible subscale scores of 36,40 , 24,52 , and 52 respectively.

\section{Posttraumatic Stress Disorder (PTSD) Checklist for DSM-5 (PCL-5). The PCL-5}

contains 20 items which are designed to assess 20 symptoms of PTSD outlined in DSM-5. Items 1-5 address Criterion B; items 6-7, Criterion C; items 8-14, Criterion D; and items 15-20, Criterion E. Criterion A (Exposure to actual or threatened death, serious injury, or sexual violence) is not assessed for with the standard version of the PCL-5; however, an additional brief qualitative assessment can be used if desired (American Psychiatric Association, 2013; Weathers et al., 2013a). For the purposes of this study, only the standard PCL-5 will be used as Criterion A is previously assumed to be related to the discovery/disclosure of the partner's sexual addiction.

The 20 items on the standard PCL-5 are endorsed using a 0 to 4 rating scale, with 0 being not at all and 4 being extremely. Intermediate response categories are: (1) a little bit; (2) moderately; and (3) quite a bit (Weathers et al., 2013b). Previous versions of the PCL have displayed commendable psychometric properties (see Adkins, Weathers, McDevitt-Murphy, \& Daniels, 2008; Blanchard, Jones-Alexander, Buckley, \& Forneris, 1996; Holliday, Smith, North, \& Suris, 2015; Palmieri, Weathers, Difede, \& King, 2007; Ruggiero, Del Ben, Scotti, \& Rabalais, 2003; Weathers, Litz, Herman, Huska, \& Keane, 1993; Wilkins, Lang, \& Norman, 2011), and the PCL-5 also shows strong internal consistency $(\alpha=0.94)$ and test-retest reliability 
$(\mathrm{r}=0.82)$, along with favorable convergent and discriminant validity (see Armour et al., 2015;

Blevins, Weathers, Davis, Witte, \& Domino, 2015; Price, Szafranski, van Stolk-Cooke, \& Gros, 2016; Wortmann et al., 2016).

A total score of 33 (out of a possible 80) on the PCL-5 has been recommended as reasonable value for the cut-point score, meaning clinicians are encouraged to further evaluate clients whose scores are above 33 (Bovin et al., 2016; Weathers et al., 2013a). Subscale (or cluster) scores for the PCL-5 can also be obtained by calculating score totals for specific sets of items (Weathers et al., 2013a). The clusters and requirements for provisional diagnoses are noted in Appendix C along with the PCL-5 items.

Adverse Childhood Experiences (ACE) Module. In 1995, the Centers for Disease Control and Prevention (CDC) partnered with Kaiser Permanente to study the effect of earlychildhood abuse and neglect on later-life health and well-being (CDC, 2016; Felitti et al., 1998). This study asked participants about adverse childhood experiences (ACEs) utilizing a variety of questionnaires, and ultimately found that the higher an individual's ACE score was, the higher their risk of later-life consequences, such as poor mental and physical health, and other social consequences (Felitti et al., 1998; Redding, n.d.).

In 2009, the CDC incorporated several questions regarding adverse childhood experiences (ACEs) into the annual Behavioral Risk Factor Surveillance System (BRFSS; CDC, 2016). Since its incorporation, the CDC has gathered ACE data from nearly 200,000 individual in 32 states and the District of Columbia (CDC, 2016). For the purposes of the current study, the 11-question BRFSS ACE module will be used.

The ACE module includes three subscales: Household dysfunction (items 1-5); Emotional/physical abuse (items 6-8); and Sexual abuse (items 9-11). These subscales and 
associated items combine to produce an overall scale (Ford et al., 2014). In terms of psychometric properties for the ACE module, overall internal consistency is reported to be 0.78 , with subscale alphas ranging between 0.61 and 0.80 (Ford et al., 2014).

Benevolent Childhood Experiences (BCE) Questionnaire. The BCE Questionnaire is a relatively new instrument modeled after the ACE Scale. It was designed to assess the effect of favorable early-life experiences, including both internal and external perceptions of safety, security, and support, on trauma-related symptomatology (Narayan, Rivera, Bernstein, Harris, \& Lieberman, 2018). In this study, the BCE was shown to be a significant predictor of PTSD symptoms $(\mathrm{B}=-2.95, p<0.01)$, and negatively correlated with the $\mathrm{ACE}(r=-0.37, p<0.01)$. Test-retest reliability of the measure was reported at $r=0.80(p<0.01)$. Additional psychometric properties of the BCE are not currently available; however, the scale's development is outlined in the 2018 article by Narayan et al.

Composite Codependency Scale (CCS). The CCS was developed by researchers in Australia who sought a more comprehensive, standardized assessment of codependence that could provide empirical evidence for the underlying facets of codependency, which include the following: external focusing; self-sacrifice; interpersonal control; and emotional suppression (Marks, Blore, Hine, \& Dear, 2012). The Holyoake Codependency Index (HCI) is the most commonly used measure of codependency and has adequate psychometric properties $(\alpha=0.83$ to 0.84; test-retest $r=0.88$ ). However, the HCI assesses only two of the four factors (external focus and self-sacrifice). As such, in order to create the CCS, researchers utilized the entire HCI, as well as select items from the Spann-Fischer Codependency Scale, the Codependency Assessment Tool, and the Codependent Questionnaire in order to address the additional factors of interpersonal control and self-sacrifice. The resulting scale includes 19 items which assess three 
latent factors: self-sacrifice (items 1-7); interpersonal control (items 8-13); and emotional suppression (items 14-19). Internal consistency for the scale and its subscales ranges from 0.77 to 0.85 (Marks et al., 2012).

\section{Data Analyses}

Data analyses were conducted using IBM SPSS 26 statistical software programs. Of particular interest were the bivariate correlations and regression coefficients for TIPSA scores and scores from other measures included in the study. Ultimately, the goal of the data analyses was to provide evidence for the reliability and validity of TIPSA score interpretation.

To test for type of missingness, the Missing Value Analysis (MVA) function in SPSS 26 was utilized. This analysis includes Little's Missing Completely at Random (MCAR) test, which provides a $p$-value associated with the probability of committing a Type I error (rejecting the null hypothesis that data are missing completely at random). The responses for each measure were analyzed in the presence of the demographic variables, which were treated as categories, and the results for all missing value analyses are included in Table 2.

Results of the MVA indicated that missing responses on all measures except for the ACE were MCAR. Because the missing ACE values were not MCAR, listwise deletion was not recommended. In addition, 45 total cases contributed to missing data. As that accounted for nearly $25 \%$ of cases, listwise deletion was not utilized. Of the 111 total measure variables, 44 (39.64\%) had missing values. Missing values were imputed utilizing the multiple imputation function of SPSS. This function created a new data set with the original values, along with five variations of the data set containing values imputed utilizing linear regression. A total of 63 values $(0.296 \%)$ were imputed. The RANDBETWEEN function in EXCEL was used to randomly select a number between one and five in order to select an imputed dataset for use in 
the final analyses. The number generated was two, thus the second imputed data set was utilized for analysis.

\section{Results}

\section{Reliability}

In order to examine the internal-consistency (reliability) of the TIPSA and the other measures included in this study, the Reliability Analysis function in SPSS 26 was utilized. All estimates for the overall TIPSA scale and associated subscales were above 0.70 , suggesting that all scales meet an acceptable level of internal consistency. In addition, all other alpha estimates were above 0.70 , with the exception of the ACE-Household subscale which was below 0.60 and therefore considered to be in the unacceptable range. As such, individual ACE subscales were ignored, and only the ACE total scale was utilized in subsequent analyses. The resulting alphas and previously reported values are displayed in Table 3.

\section{Convergent Validity}

To establish convergent validity, the TIPSA and the PCL-5 were compared utilizing both bivariate correlation and regression analysis. As the PCL-5 does not include items that address Criterion A for PTSD, the TIPSA-A subscale was excluded from the overall TIPSA scale score in order to more accurately compare the two measures. Bivariate correlation of the total scores produced a Pearson's $r$ of $0.851(p=5.541$ E-55), which indicated a large effect size according to Cohen's (1992) effect size criteria. Single linear regression produced an $\mathrm{R}^{2}$ value of 0.724 , with an unstandardized beta coefficient of 1.561 , signifying that over $72 \%$ of the variance in TIPSA scores is accounted for by the relationships between the TIPSA and the PCL-5.

In addition to total measure scores, the subscale scores for the TIPSA and the PCL-5 were also compared. Bivariate correlations showed significant relationships between all subscale 
scores, with directly associated subscales being the mostly highly correlated. Correlation results are depicted in Table 4.

\section{Divergent Validity}

In order to establish divergent validity, the TIPSA and the CCS were compared utilizing bivariate correlation and regression analysis. Bivariate correlation of the total scores produced a Pearson's $r$ of 0.292 ( $p=3.9$ E-5; small effect size), while regression analysis produced an unstandardized beta coefficient of 0.749 , with an $\mathrm{r}^{2}$ value of 0.085 , indicating that $8.5 \%$ of the variance in TIPSA scores was explained by the relationship between the TIPSA and the CCS.

\section{Additional Influences}

In order to address the concern that early-life experiences unduly affect experiences of betrayal trauma, correlation between the TIPSA and both the ACE and BCE were examined. Overall, the TIPSA was not strongly correlated with either instrument (low effect size). Regression analyses were also utilized to examine the strength of influence of all possible predictors on TIPSA scores. Predictors were added utilizing both block entry (all predictors at once) and stepwise entry (analysis of all possible combinations of predictors). Both analyses indicated that PCL-5 total score was the only significant predictor of TIPSA total score. The same analyses were utilized to examine the relationship between PCL-5 total score and the ACE and BCE scores. Results of these analyses are included in Tables 5 through 7.

\section{Discussion}

The aim of this study was to assess the reliability and validity of the TIPSA, a measure of trauma symptoms related to the disclosure and/or discovery of a partner's extra-relationship sexual behaviors. It was hypothesized that the internal-consistency coefficients for the TIPSA would exceed an acceptable cut-off of 0.70 . As acceptable reliability is requisite in order to 
establish validity, verifying reliability was a necessary first step in this study. Results of reliability testing produced alphas for both the TIPSA subscales (ranging from 0.73 to 0.86 ) and the total scale (0.94 for both with and without Criterion A). Each of these values was above the conventional standard for acceptability of 0.70 , thus meeting the necessary criteria to proceed with the process for establishing validity. In addition to meeting the acceptable cut-off score, the obtained reliability estimates mirrored previously reported reliability estimates (where available). Thus, results of the analyses endorsed the research hypothesis that responses to the TIPSA would produce acceptable reliability coefficients.

In terms of validity, the hypothesis that the TIPSA and the PCL-5 would be significantly positively correlated was also supported by the results. The two instruments were significantly correlated, with an $r$ value of $0.851\left(r^{2}=0.724\right.$; large effect size $)$. This suggests that the TIPSA and the PCL-5 are measuring the same construct. In addition to the correlation coefficients, regression analyses showed the PCL-5 to be a significant predictor of TIPSA scores, with the PCL-5 being the only predictor retained in a stepwise analysis of all possible predictors. The evidence provided by both the regression analyses and the correlation coefficients therefore support the hypothesis that the TIPSA and PCL-5 are significantly correlated. Additionally, given the magnitude of the correlation coefficients and the strength of the regression coefficients, it appears that the TIPSA and PCL-5 are measuring the same construct. This therefore establishes convergent validity of the TIPSA as a measure of trauma symptoms.

The third hypothesis that the TIPSA and the CCS would not be significantly correlated was somewhat supported by the findings. While the correlation between the two instruments was significant $(r=0.292 ; p=3.90 \mathrm{E}-5)$, the effect size was small, with an $r^{2}$ of 0.085 . Compared to the relationships between the TIPSA and the PCL-5, the relationship between the 
TIPSA and CCS does not appear to meaningfully impact TIPSA scores. In addition, the CCS was not a significant predictor of TIPSA scores when examined in the presence of multiple predictors. This is another indication that the relationship between CCS scores and TIPSA scores is weak and uninformative. Thus, there appears to be sufficient evidence to support the general hypothesis that the TIPSA and CCS are measuring different constructs. With the burden of proof met, it appears that divergent validity of the TIPSA has been established; and that the TIPSA is measuring something other than codependency.

Finally, the hypotheses that neither the BCE nor the ACE would be significantly correlated with TIPSA scores were also somewhat supported by the results of the analyses. As with the CCS, scores from the BCE and ACE were both significantly correlated with TIPSA scores; however, the effect sizes were again both small $(<0.3)$. In the regression analyses, neither instrument was retained as a significant predictor of TIPSA scores in the presence of all other predictors when utilizing both block entry and stepwise analyses. This suggests that previous childhood experiences, whether positive or negative, are not strongly related to TIPSA scores. Accordingly, there appears to be enough evidence to establish divergent validity between the TIPSA and both the BCE and ACE; meaning, the TIPSA is not measuring the effects of childhood experiences.

In regards to the relationship between the PCL-5 and the BCE and ACE, the results were more mixed. The correlation coefficient of 0.308 was significant and represents a moderate effect size. In addition, the ACE was a significant predictor of PCL-5 scores in both the block entry and stepwise regression analyses. This suggests there is a stronger relationship between PCL-5 scores and ACE scores than there is between TIPSA and ACE scores. While this is an interesting result, as the PCL-5 was not the focus of this study we do not address these findings 
further. However, this association may warrant further investigation in research outside of the current study.

\section{Conclusions}

Power analysis completed prior to the study indicated that the sample size of at least 193 was sufficient to detect correlations of at least 0.20 at the 0.05 significance level. As such, the sample size of 192 was deemed adequate for the intended analyses. Based on the results from the various statistical methods, there appears to be sufficient evidence to establish convergent validity of the TIPSA as a measure of trauma symptoms. Moreover, statistical evidence indicates the existence of only a weak relationship between the TIPSA and CCS, suggesting that the two instruments are not measuring the same construct, thus establishing divergent validity of the TIPSA. Finally, neither the BCE nor the ACE was strongly correlated with the TIPSA, indicating that TIPSA scores are also likely independent of previous exposure to either benevolent or adverse childhood experiences, which also serves to establish divergent validity of the TIPSA.

\section{Limitations}

The sample for this study was a self-selected convenience sample. As such, generalizability of the findings may be more limited in this instance than if a different sampling technique had been used. Additionally, while the sample size was adequate for the initial study design, a larger sample would have provided a more refined ability to discriminate between the significance and effect size of correlation coefficients.

\section{Suggestions and Future Research}

In this study, the TIPSA_A subscale was excluded from analyses as the PCL-5 did not include items for that criterion of PTSD. Because Criterion A is more easily assessed verbally or 
with one free-response item, and the reliability of the TIPSA is nearly identical with and the without the A subscale, it is suggested that the TIPSA be revised to include only those items that address criteria B through E. This will serve to shorten the length of the TIPSA and reduce the amount of time needed for administration without affecting the reliability of the instrument.

Currently, the TIPSA provides only screening information regarding trauma in the context of sexual addiction. Exploring the possibility of revising the TIPSA to be used as an outcome or diagnostic assessment is advised. This will increase the utility of the instrument, and provide clinicians with evidence that directly ties to the diagnostic criteria for PTSD. The PCL-5 currently provides a cut-score and interpretation of items that could be used as a template for future versions of the TIPSA.

Finally, an examination of both the structural and measurement invariance of the TIPSA is another possible area study. Of particular interest in a future study would be invariance between male and female respondents. Other groups of interest may include religion, relationship status, and length of time since the disclosure or discovery of the addiction. 


\section{References}

Adkins, J. W., Weathers, F. W., McDevitt-Murphy, M., \& Daniels, J. B. (2008). Psychometric properties of seven self-report measures of posttraumatic stress disorder in college students with mixed civilian trauma exposure. Journal of Anxiety Disorders, 22(8), 13931402. doi:10.1016/j.janxdis.2008.02.002

American Educational Research Association (AERA), American Psychological Association (APA), National Council on Measurement in Education (NCME), \& Joint Committee on Standards for Educational and Psychological Testing (U.S.). (2014). Standards for educational and psychological testing. Washington, DC: AERA.

American Psychiatric Association. (2000). Diagnostic and statistical manual of mental disorders (4th ed., Text Revision ed.). Washington, DC: Author.

American Psychiatric Association. (2013). Diagnostic and statistical manual of mental disorders (5th ed.). Arlington, VA: American Psychiatric Publishing.

Anders, S. L., Frazier, P. A., \& Frankfurt, S. B. (2011). Variations in Criterion A and PTSD rates in a community sample of women. Journal of Anxiety Disorders, 25(2), 176-184. doi:10.1016/j.janxdis.2010.08.018

Armour, C., Tsai, J., Durham, T. A., Charak, R., Biehn, T. L., Elhai, J. D., \& Pietrzak, R. H. (2015). Dimensional structure of DSM-5 posttraumatic stress symptoms: Support for a hybrid Anhedonia and Externalizing Behaviors model. Journal of Psychiatric Research, 61, 106-113. doi:10.1016/j.jpsychires.2014.10.012

Baird, M. H. (2011). What can the twelve steps do for me? In S. Carnes (Ed.), Mending a shattered heart: A guide for partners of sex addicts (2nd ed.; pp. 113-130). Carefree, AZ: Gentle Path Press. 
Blanchard, E. B., Jones-Alexander, J., Buckley, T. C., \& Forneris, C. A. (1996). Psychometric properties of the PTSD Checklist (PCL). Behaviour Research and Therapy, 34(8), 669673.

Blevins, C. A., Weathers, F. W., Davis, M. T., Witte, T. K., \& Domino, J. L. (2015). The Posttraumatic Stress Disorder Checklist for DSM-5 (PCL-5): Development and initial psychometric evaluation. Journal of Traumatic Stress, 28, 489-498.

doi:10.1002/jts.22059

Bovin, M. J., Marx, B. P., Weathers, F. W., Gallagher, M. W., Rodriguez, P., Schnurr, P. P., \& Keane, T. M. (2016). Psychometric properties of the PTSD Checklist for Diagnostic and Statistical Manual of Mental Disorders-Fifth Edition (PCL-5) in veterans. Psychological Assessment, 28(11), 1379-1391. doi:10.1037/pas0000254

Briere, J. N., \& Scott, C. (2015). Principles of trauma therapy: A guide to symptoms, evaluation, and treatment (DSM-5 Update) (2nd ed.). Thousand Oaks, CA: Sage Publications, Inc.

Carnes, S. (2011). What is sex addiction. In S. Carnes (Ed.), Mending a shattered heart: A guide for partners of sex addicts (pp. 7-24). Carefree, AZ: Gentle Path Press.

Carnes, S., \& O'Connor, S. (2016). Confirmatory analysis of the Partner Sexuality Survey. Sexual Addiction \& Compulsivity, 23(1), 141-153. doi:10.1080/10720162.2015.1039151

Centers for Disease Control and Prevention (CDC). (2016, April 1). Adverse Childhood Experiences (ACEs). Retrieved from https://www.cdc.gov/violenceprevention/acestudy/index.html Cohen, J. (1992). A power primer. Psychological Bulletin, 112(1), 155-159. 
Cook, A., Spinazzola, J., Ford, J., Lanktree, C., Blaustein, M., Cloitre, M., . . van der Kolk, B. A. (2017). Complex trauma in children and adolescents. Psychiatric Annals, 35(5), 390398.

Ellis, P. D. (2010). The essential guide to effect sizes. Statistical power, meta-analysis, and the interpretation of eesearch results. New York, NY: Cambridge University Press.

Faul, F., Erdfelder, E., Buchner, A., \& Lang, A. G. (2009). Statistical power analyses using G*Power 3.1: Tests for correlation and regression analyses. Behavior Research Methods, 41(4), 1149-1160. doi:10.3758/BRM.41.4.1149

Felitti, V. J., Anda, R. F., Nordenberg, D., Williamson, D. F., Edwards, A. M., Edwards, V., ... Marks, J. S. (1998). Relationship of childhood abuse and household dysfunction to many of the leading causes of death in adults: The Adverse Childhood Experiences (ACE) Study. American Journal of Preventive Medicine, 14(4), 245-258.

Fitness, J. (2001). Betrayal, rejection, revenge, and forgiveness: An interpersonal script approach. In M. R. Leary (Ed.), Interpersonal rejection (pp. 73-104). New York, NY: Oxford University Press.

Ford, D. C., Merrick, M. T., Parks, S. E., Breiding, M. J., Gilbert, L. K., Edwards, V. J., . . Thompson, W. W. (2014). Examination of the factorial structure of Adverse Childhood Experiences and recommendations for three subscale scores. Psychological Violence, 4(4), 432-444. doi:10.1037/a0037723

Freyd, J. J. (1991). Memory repression, dissociative states, and other cognitive control processes involved in adult sequelae of childhood trauma. Paper presented at the Second Annual Conference on a Psychodynamics - Cognitive Science Interface, San Francisco, CA. 
Freyd, J. J. (2003). What is a betrayal trauma? What is betrayal trauma theory? Retrieved from https://scholarsbank.uoregon.edu/xmlui/bitstream/handle/1794/65/defineBT.html?sequen $\mathrm{ce}=1$

Freyd, J. J. (2013). Preventing betrayal. Journal of Trauma \& Dissociation, 14(5), 495-500. doi:10.1080/15299732.2013.824945

Freyd, J. J., \& Birrell, P. (2013). Blind to betrayal: Why we fool ourselves we aren't being fooled. Hoboken, NJ: Wiley.

Giordano, A. L., Prosek, E. A., Stamman, J., Callahan, M. M., Loseu, S., Bevly, C. M., . . . Chadwell, K. (2016). Addressing trauma in substance abuse treatment. Journal of Alcohol and Drug Education, 60(2), 55-71.

Gomez, J. M., Lewis, J. K., Noll, L. K., Smidt, A. M., \& Birrell, P. J. (2016). Shifting the focus: Nonpathologizing approaches to healing from betrayal trauma through an emphasis on relational care. Journal of Trauma and Dissociation, 17(2), 165-185.

doi:10.1080/15299732.2016.1103104

Holliday, R., Smith, J., North, C., \& Suris, A. (2015). Developing the PTSD Checklist-I/F for the DSM-IV (PCL-I/F): Assessing PTSD symptom frequency and intensity in a pilot study of male veterans with combat-related PTSD. Behavioral Sciences, 5(1), 59-69. doi:10.3390/bs5010059

Kafka, M. P. (2013). The development and evolution of the criteria for a newly proposed diagnosis for DSM-5: Hypersexual disorder. Sexual Addiction \& Compulsivity, 20(1-2), 19-26. doi:10.1080/10720162.2013.768127 
Kelley, L. P., Weathers, F. W., Mason, E. A., \& Pruneau, G. M. (2012). Association of life threat and betrayal with posttraumatic stress disorder symptom severity. Journal of Traumatic Stress, 25(4), 408-415. doi:10.1002/jts.21727

Kraus, S. W., Voon, V., \& Potenza, M. N. (2016). Should compulsive sexual behavior be considered an addiction? Addiction, 111(12), 2097-2106. doi:10.1111/add.13297

Marks, A. D. G., Blore, R. L., Hine, D. W., \& Dear, G. E. (2012). Development and validation of a revised measure of codependency. Australian Journal of Psychology, 64(3), 119-127. doi:10.1111/j.1742-9536.2011.00034.x

Minwalla, O. (2012, Jul 23). Partners of sex addicts need treatment for trauma. Retrieved from http://nationalpsychologist.com/2012/07/partners-of-sex-addicts-need-treatment-for-trau ma

Minwalla, O. (n.d.). SAI trauma model. Retrieved from http://theinstituteforsexualhealth.com/about-us/sai-trauma-model/

Narayan, A. J., Rivera, L. M., Bernstein, R. E., Harris, W. W., \& Lieberman, A. F. (2018). Positive childhood experiences predict less psychopathology and stress in pregnant women with childhood adversity: A pilot study of the Benevolent Bhildhood Experiences (BCEs) scale. Child Abuse \& Neglect, 78, 19-30. doi:10.1016/j.chiabu.2017.09.022

Palmieri, P. A., Weathers, F. W., Difede, J., \& King, D. W. (2007). Confirmatory factor analysis of the PTSD Checklist and the Clinician-Administered PTSD Scale in disaster workers exposed to the World Trade Center Ground Zero. Journal of Abnormal Psychology, 116(2), 329-341. doi:10.1037/0021-843X.116.2.329

Platt, M. G., \& Freyd, J. J. (2015). Betray my trust, shame on me: Shame, dissociation, fear, and betrayal trauma. Psychological Trauma, 7(4), 398-404. doi:10.1037/tra0000022 
Price, M., Szafranski, D. D., van Stolk-Cooke, K., \& Gros, D. F. (2016). Investigation of abbreviated 4 and 8 item versions of the PTSD Checklist 5. Psychiatry Research, 239, 124-130. doi:10.1016/j.psychres.2016.03.014

Redding, C. (n.d.). The adverse childhood experiences study: A springboard to hope. Retrieved from http://acestudy.org/index.html

Ruggiero, K. J., Del Ben, K., Scotti, J. R., \& Rabalais, A. E. (2003). Psychometric properties of the PTSD Checklist-Civilian Version. Journal of Traumatic Stress, 16(5), 495-502.

Schneider, J. P., Weiss, R., \& Samenow, C. (2012). Is it really cheating? Understanding the emotional reactions and clinical treatment of spouses and partners affected by cybersex infidelity. Sexual Addiction \& Compulsivity, 19(1-2), 123-139.

doi:10.1080/10720162.2012.658344

Skinner, K. B. (2015, Aug 13). The lasting effects of sexual betrayal. Retrieved from https://www.psychologytoday.com/blog/inside-porn-addiction/201508/the-lasting-effects -sexual-betrayal

Smith, C. P., \& Freyd, J. J. (2014). Institutional betrayal. American Psychologist, 69(6), 575587. doi:10.1037/a0037564

Steffens, B. A. (2005). The effects of disclosure on wives of sexual addicts (Doctoral dissertation). Retrieved from https://search.proquest.com/docview/305353623?accountid=4488

Steffens, B. A., \& Rennie, R. L. (2006). The traumatic nature of disclosure for wives of sexual addicts. Sexual Addiction \& Compulsivity, 13(2-3), 247-267. doi:10.1080/10720160600870802 
Stokes, S. S. (2017). An examination of the psychometric properties of the Trauma Inventory for Partners of Sex Addicts (TIPSA) (Doctoral dissertation). Retrieved from https://scholarsarchive.byu.edu/cgi/viewcontent.cgi?article=7500\&context=etd.

van der Kolk, B. A. (2005). Developmental Trauma Disorder: Toward a rational diagnosis for children with complex trauma histories. Psychology Module, 35(5), 401-408.

van der Kolk, B. A., Roth, S., Pelcovitz, D., Sunday, S., \& Spinazzola, J. (2005). Disorders of extreme stress: The empirical foundation of a complex adaptation to trauma. Journal of Traumatic Stress, 18(5), 389-399. doi:10.1002/jts.20047

Vogeler, H. A. (2017). An examination of the factor structure of the Trauma Inventory for Partners of Sex Addicts (TIPSA) (Doctoral dissertation). Retrieved from https://scholarsarchive.byu.edu/cgi/viewcontent.cgi?article=7654\&context=etd

Vogeler, H. A., Fischer, L., Sudweeks, R. R., \& Skinner, K. B. (2018). An examination of the factor structure of the Trauma Inventory for Partners of Sex Addicts (TIPSA). Sexual Addiction \& Compulsivity, （1), 46-61. doi:10.1080/10720162.2018.1452086

Weathers, F. W., \& Keane, T. M. (2007). The Criterion A problem revisited: Controversies and challenges in defining and measuring psychological trauma. Journal of Traumatic Stress, 20(2), 107-121. doi:10.1002/jts.20210

Weathers, F. W., Litz, B. T., Herman, D. S., Huska, J. A., \& Keane, T. M. (1993). The PTSD Checklist: Reliability, validity, and diagnostic utility. Paper presented at the International Society for Traumatic Stress Studies, San Antonio, TX.

Weathers, F. W., Litz, B. T., Keane, T. M., Palmieri, P. A., Marx, B. P., \& Schnurr, P. P. (2013a). The PTSD Checklist for DSM-5 (PCL-5). Retrieved from https://www.ptsd.va.gov/professional/assessment/adult-sr/ptsd-checklist.asp 
Weathers, F. W., Litz, B. T., Keane, T. M., Palmieri, P. A., Marx, B. P., \& Schnurr, P. P. (2013b). The PTSD Checklist for DSM-5 (PCL-5) - Standard [Measurement instrument]. Retrieved from http://www.ptsd.va.gov/professional/assessment/adult-sr/ptsdchecklist.asp

Whisman, M. A., \& Wagers, T. P. (2005). Assessing relationship betrayals. Journal of Clinical Psychology, 61(11), 1383-1391. doi:10.1002/jclp.20188

Wilkins, K. C., Lang, A. J., \& Norman, S. B. (2011). Synthesis of the psychometric properties of the PTSD checklist (PCL) military, civilian, and specific versions. Depression and Anxiety, 28(7), 596-606. doi:10.1002/da.20837

Wortmann, J. H., Jordan, A. H., Weathers, F. W., Resick, P. A., Dondanville, K. A., Hall-Clark, B., . . Litz, B. T. (2016). Psychometric analysis of the PTSD Checklist-5 (PCL-5) among treatment-seeking military service members. Psychological Assessment, 28(11), 1392-1403. doi:10.1037/pas0000260 


\section{Tables}

\section{Table 1}

Demographics of Respondents $(n=192)$

\begin{tabular}{lrrlrr}
\hline Category & $\mathrm{n}$ & \multicolumn{1}{c}{$\%$} & Category & $\mathrm{n}$ & $\%$ \\
\hline Gender & & & Relationship Status & \\
$\quad$ Female & 200 & 100.0 & Committed Relationship & 39 & 20.3 \\
Age & & & Married & 123 & 64.1 \\
$18-24$ & 13 & 6.8 & Married, but separated & 18 & 9.4 \\
$25-34$ & 47 & 24.5 & Divorced & 5 & 2.6 \\
$35-44$ & 59 & 30.7 & Other & 7 & 3.6 \\
$45-54$ & 46 & 24.0 & Education & 7 & 3.6 \\
$55-64$ & 21 & 10.9 & Less the High School & \\
65-74 & 6 & 3.0 & High School Graduate & 27 & 14.1 \\
Race/Ethnicity & & & Some College & 56 & 29.2 \\
White & 160 & 83.3 & 2-year Degree & 25 & 13.0 \\
Black or African American & 4 & 2.1 & 4-year Degree & 44 & 22.9 \\
Hispanic/Latino & 8 & 4.2 & Masters/Doctorate & 26 & 13.5 \\
American Indian/Alaska Native & 1 & 0.5 & Professional Degree (MD, JD) & 4 & 2.1 \\
Asian & 2 & 1.0 & Unreported & 3 & 1.6 \\
Native Hawaiian/Pacific Islander & 1 & 0.5 & Length of Time Knowing about Behavior & \\
Multiracial & 5 & 2.6 & Less than 1 month & 21 & 10.9 \\
Prefer not to answer & 6 & 3.1 & 2-3 months & 13 & 6.8 \\
Other/Unreported & 5 & 2.6 & 4-6 months & 9 & 4.7 \\
Religious Affiliation & & & 7-12 months & 16 & 8.3 \\
Christian & 114 & 59.4 & More than 1 year, less than 2 & 20 & 10.4 \\
Muslim & 1 & 0.5 & More than 2 years, less than 5 & 46 & 24.0 \\
Jewish & 4 & 2.0 & More than 5 years & 67 & 34.9 \\
Spiritual, but not religious & 45 & 23.4 & & \\
Other & 22 & 11.5 & & \\
Unreported & & 3.1 & & & \\
\hline & & & &
\end{tabular}


Table 2

Missing Value Analysis ( $n=192)$

\begin{tabular}{rcccccr}
\hline \multirow{2}{*}{$\begin{array}{c}\text { Measure Name } \\
\text { \# of Items) }\end{array}$} & \multicolumn{2}{c}{ \# Missing per Item } & \multicolumn{2}{c}{ \# Missing per Case } & \# Cases & Little's \\
Low (\%) & High (\%) & Low (\%) & High (\%) & Contributing (\%) & MCAR \\
\hline TIPSA (51) & $0(0.00)$ & $2(1.00)$ & $0(0.00)$ & $3(5.88)$ & $13(6.77)$ & 0.873 \\
PCL-5 (20) & $0(0.00)$ & $3(1.60)$ & $0(0.00)$ & $2(10.00)$ & $11(5.73)$ & 0.959 \\
BCE (10) & $2(1.00)$ & $2(1.00)$ & $0(0.00)$ & $2(20.00)$ & $10(5.21)$ & 0.234 \\
ACE (11) & $0(0.00)$ & $3(1.60)$ & $0(0.00)$ & $2(18.18)$ & $11(5.73)$ & 0.018 \\
CCS (19) & $0(3.50)$ & $2(1.00)$ & $0(0.00)$ & $1(5.26)$ & $6(3.13)$ & 0.530 \\
\hline TOTAL (11) & & & & $45(23.44)$ & 0.523 \\
\hline
\end{tabular}

Note. Little's MCAR values $>0.05$ suggest that data is missing completely at random

Table 3

Reliability Estimates: Cronbach's Alpha ( $\alpha$ )

\begin{tabular}{|c|c|c|c|c|}
\hline Measure & Mean & $\begin{array}{r}\text { Standard } \\
\text { Deviation }\end{array}$ & $\begin{array}{r}\text { Expected } \\
\text { Reliability }\end{array}$ & $\begin{array}{r}\text { Observed } \\
\text { Reliability }\end{array}$ \\
\hline TIPSA-A & 6.7077 & 4.396 & $0.80^{*}$ & 0.73 \\
\hline TIPSA-B & 24.906 & 8.124 & $0.89^{*}$ & 0.87 \\
\hline TIPSA-C & 12.995 & 5.143 & $0.70 *$ & 0.78 \\
\hline TIPSA-D & 32.712 & 9.992 & $0.87 *$ & 0.86 \\
\hline TIPSA-E & 31.399 & 8.561 & $0.86^{*}$ & 0.86 \\
\hline TIPSA-Total & 108.719 & 28.793 & $0.95^{*}$ & 0.94 \\
\hline TIPSA-No-A-Total & 102.012 & 26.855 & --- & 0.94 \\
\hline PCL-5-B & 12.871 & 4.157 & --- & 0.80 \\
\hline PCL-5-C & 4.952 & 2.290 & --- & 0.83 \\
\hline PCL-5-D & 17.764 & 5.947 & --- & 0.85 \\
\hline PCL-5-E & 14.013 & 5.088 & --- & 0.79 \\
\hline PCL-5 & 49.599 & 14.636 & 0.96 & 0.92 \\
\hline ACE-Household & 1.645 & 1.394 & 0.61 & 0.58 \\
\hline ACE-Emotional & 1.261 & 1.147 & 0.70 & 0.73 \\
\hline ACE-Sexual & 0.817 & 1.083 & 0.80 & 0.77 \\
\hline ACE-Total & 7.398 & 2.464 & 0.78 & 0.75 \\
\hline $\mathrm{BCE}$ & 3.724 & 2.689 & $0.80 * *$ & 0.79 \\
\hline CCS-SS & 14.510 & 5.137 & 0.77 & 0.75 \\
\hline CCS-IC & 16.460 & 4.661 & 0.80 & 0.85 \\
\hline CCS-ES & 15.094 & 5.108 & 0.83 & 0.85 \\
\hline CCS-Total & 46.063 & 10.482 & 0.85 & 0.83 \\
\hline
\end{tabular}

*Rho estimates **Test-retest reliability estimate

---No previously reported estimate available 
Table 4

Correlation Coefficients Between Subscales

\begin{tabular}{crrrrrr}
\hline \multirow{2}{*}{ Subscales } & \multicolumn{1}{c}{$\begin{array}{c}\text { PCL-5_B } \\
r(p=)\end{array}$} & $\begin{array}{c}\text { PCL-5_C } \\
r(p=)\end{array}$ & $\begin{array}{c}\text { PCL-5_D } \\
r(p=)\end{array}$ & $\begin{array}{c}\text { PCL-5_E } \\
r(p=)\end{array}$ & $\begin{array}{r}\text { PCL-5 Total } \\
r(p=)\end{array}$ & $\begin{array}{r}\text { TIPSA Total } \\
r(p=)\end{array}$ \\
\hline \multirow{2}{*}{ TIPSA_B } & $\mathbf{0 . 7 4 0}$ & 0.513 & 0.579 & 0.588 & 0.730 & 0.864 \\
& $(1.67 E-34)$ & $(2.78 E-14)$ & $(1.45 E-18)$ & $(3.04 E-19)$ & $(3.22 E-33)$ & $(1.64 E-58)$ \\
TIPSA_C & 0.495 & $\mathbf{0 . 5 3 8}$ & 0.676 & 0.610 & 0.711 & 0.772 \\
& $(2.86 E-13)$ & $(8.43 E-16)$ & $(5.53 E-27)$ & $(6.07 E-21)$ & $(6.32 E-31)$ & $(3.25 E-39)$ \\
TIPSA_D & 0.494 & 0.354 & $\mathbf{0 . 7 1 7}$ & 0.519 & 0.667 & 0.841 \\
& $(3.26 E-13)$ & $(4.73 E-7)$ & $(1.46 E-31)$ & $(1.24 E-14)$ & $(4.16 E-26)$ & $(1.81 E-52)$ \\
TIPSA_E & 0.635 & 0.475 & 0.651 & $\mathbf{0 . 7 2 1}$ & 0.770 & 0.872 \\
& $(4.47 E-23)$ & $(3.24 E-12)$ & $(1.43 E-24)$ & $(4.55 E-32)$ & $(6.30 E-39)$ & $(5.77 E-61)$ \\
\hline \multirow{2}{*}{ TIPSA Total } & 0.705 & 0.541 & 0.779 & 0.718 & $\mathbf{0 . 8 5 1}$ & \\
& $(3.77 E-30)$ & $(5.09 E-16)$ & $(2.36 E-40)$ & $(1.14 E-31)$ & $(5.54 E-55)$ & \\
PCL-5 Total & 0.808 & 0.659 & 0.876 & 0.896 & & \\
& $(1.91 E-45)$ & $(3.05 E-25)$ & $(3.48 E-62)$ & $(5.16 E-69)$ & & \\
\hline
\end{tabular}

Note. Bold values represent the relationship between corresponding subscales

Table 5

Zero-Order Correlations with TIPSA

\begin{tabular}{|c|c|c|c|c|c|c|c|c|}
\hline \multirow{2}{*}{ Instrument } & \multicolumn{2}{|l|}{ TIPSA } & \multirow{2}{*}{$\begin{array}{l}\text { PCL-5 } \\
r(p=)\end{array}$} & \multicolumn{2}{|r|}{$\mathrm{BCE}$} & \multicolumn{3}{|c|}{$\mathrm{ACE}$} \\
\hline & $r(p=)$ & $r^{2}$ & & $r^{2}$ & $r(p=)$ & $r^{2}$ & $r(p=)$ & $r^{2}$ \\
\hline PCL-5 & $\begin{array}{r}0.851 \\
(5.54 E-55)\end{array}$ & 0.724 & & & & & & \\
\hline $\mathrm{BCE}$ & $\begin{array}{r}-0.173 \\
(1.70 E-2)\end{array}$ & 0.030 & $\begin{array}{r}-0.185 \\
(1.00 E-2)\end{array}$ & 0.034 & & & & \\
\hline $\mathrm{ACE}$ & $\begin{array}{r}0.244 \\
(1.00 E-3)\end{array}$ & 0.060 & $\begin{array}{r}0.308 \\
(1.40 E-5)\end{array}$ & 0.095 & $\begin{array}{r}-0.452 \\
(5.15 E-11)\end{array}$ & 0.204 & & \\
\hline CCS & $\begin{array}{r}0.292 \\
(3.90 E-5)\end{array}$ & 0.085 & $\begin{array}{r}0.263 \\
(2.30 E-4)\end{array}$ & 0.069 & $\begin{array}{r}-0.251 \\
(4.36 E-4)\end{array}$ & 0.063 & $\begin{array}{r}0.151 \\
(3.70 E-2)\end{array}$ & 0.023 \\
\hline
\end{tabular}


Table 6

Regression Analyses for TIPSA: Block Entry and Stepwise

\begin{tabular}{rcccccc}
\hline Model & $\mathrm{R}$ & $\mathrm{R}^{2}$ & Std. Error & Predictor & Beta & Sig. $(p=)$ \\
\hline Block Entry & 0.854 & 0.730 & 14.11 & (Constant) & 19.370 & 0.009 \\
& & & & PLC-5 & 1.539 & 1.65 E-49 \\
& & & BCE & -0.153 & 0.748 \\
& & & ACE & -0.322 & 0.465 \\
\multirow{3}{*}{ Stepwise } & 0.851 & \multirow{2}{*}{0.724} & \multirow{2}{*}{14.15} & CCS & 0.187 & 0.072 \\
& & & & (Constant) & 24.586 & 1.33 E-10 \\
& & & PLC-5 & 1.561 & 5.54 E-55 \\
& & & & & \\
& & & &
\end{tabular}

--Predictor excluded by Stepwise algorithm

Table 7

Regression Analyses for PCL-5: Block Entry and Stepwise

\begin{tabular}{rcccccc}
\hline Model & $\mathrm{R}$ & $\mathrm{R}^{2}$ & Std. Error & Predictor & Beta & Sig. $(p=)$ \\
\hline Block Entry & 0.857 & 0.735 & 7.62 & (Constant) & 0.656 & 0.871 \\
& & & & TIPSA & 0.449 & $1.65 \mathrm{E}-49$ \\
& & & BCE & 0.057 & 0.825 \\
& & & ACE & 0.603 & 0.011 \\
Stepwise 1 & 0.851 & \multirow{2}{*}{0.724} & \multirow{2}{*}{7.71} & CCS & 0.011 & 0.842 \\
& & & & (Constant) & 2.298 & 0.296 \\
& & & & TIPSA & 0.464 & 5.54 E-55 \\
Stepwise 2 & 0.857 & \multirow{2}{*}{0.735} & \multirow{2}{*}{7.58} & BCE, ACE \& CCS & -- & -- \\
& & & & Constant) & 1.576 & 0.469 \\
& & & & TIPSA & 0.449 & 3.04 E-52 \\
& & & & ACE & 0.584 & 0.006 \\
\end{tabular}

--Predictor excluded by Stepwise algorithm 


\section{APPENDIX A \\ Review of Literature}

\section{Defining Sexual Addiction}

Debate over the terminology regarding sexually compulsive behaviors and sexual addiction has intensified during the same 20-year period. P. Carnes (1983) book Out of the Shadows: Understanding Sexual Addiction is considered to be the seminal work that led to the popularization of the concept to sexual addiction. According to Kafka (2010), the central formulation of this model is "the repetitive misuse of sexual behavior to manage dysphoric affects (i.e., self-medication), an escalation or progression of sexual behaviors (tolerance and risk-taking), a loss of control, adverse psychosocial consequences, and a withdrawal state" (p. 383). Around the same time, the Diagnostic and Statistical Manual of Mental Disorders, 3rd ed., revised ed. (DSM-III-R; American Psychiatric Association [APA],1987) added the concept of nonparaphilic sexual addiction to the Sexual Disorders Not Otherwise Specified category by stating that individuals could experience "distress about a pattern of repeated sexual conquests or other forms of nonparaphilic sexual addiction, involving a succession of people who exist only as things to be used" (p. 296; see also Kafka, 2010). However, with the publication of DSM-IV (APA, 1994) and the subsequent DSM-IV-TR (APA, 2000), the use of the term "addiction" was discontinued.

In preparing for the release of the updated DSM-5 (APA, 2013), the workgroup for Sexual and Gender Identity Disorders proposed adding Hypersexual Disorder (HD) as a new diagnostic consideration (Reid et al., 2012). The proposed criteria for HD included sexual preoccupation; using sex to "self-medicate;" repetitively using sexual behaviors in response to stressful life events; inability to successfully reduce sexual behaviors; and repetitively engaging 
in sexual behaviors despite awareness of risk for significant physical or emotional harm to self or others (Kafka, 2013).

In regards to the name of the disorder, the term "hypersexual" was utilized, rather than "sexual addiction" or "sexual compulsivity," in order to "avoid misunderstandings or premature conclusions about possible etiology that has yet to be empirically established" (Reid et al., 2012, p. 2869). Kafka (2013) further clarified that there are essential elements of the addiction process, such as tolerance and withdrawal, that are not rigorously tested in validated rating scales that describe sexual behavior. Furthermore, he stated that, "studies linking hypersexual behavior to addictive processes using neuroimaging, biophysiology, and genetics were almost non-existent" (Kafka, 2013, p. 21).

While many maintain that addiction must involve "the self-administration of an agent to alter the experience of self or the environment," others argue that "we must also include the repetitive and harmful nature of many other behaviors in the human repertoire" (Martin \& Petry, 2005, p. 1). It has been suggested that behaviors such as gambling, eating, sex, and spending money may be just as addictive as substances (Grant, Potenza, Weinstein, \& Gorelick, 2010; Morgan, 1991; Plant \& Plant, 2009), and that these behaviors can produce the types of physiological rewards, such as decreased anxiety and an emotionally positive mood state, that may lead to addictive behavior (Grant et al., 2010; Vogeler, 2017).

In examining the commonalities between behavior- and substance-based addictions, urges, cravings, or build-up of tension commonly precede actions in both types of addictions (Vogeler, 2017). Emotional dysregulation may also contribute to these urges and feelings (Grant et al., 2010; Martin \& Petry, 2005). Furthermore, financial problems (which often lead to marital problems) also tend to be common in both types of addictions, with individuals committing 
"illegal acts such as theft, embezzlement, and writing bad checks, to either fund their addictive behavior or cope with the consequences of the behavior" (Grant et al., 2010, p. 234). Over time, just as with substance addictions, behavioral addictions have the potential to become more of a compulsion, with reinforcement changing from positive (release of anxiety) to negative (warding off withdrawal symptoms; Grant et al., 2010; Martin \& Petry, 2005; Vogeler, 2017). Individuals who struggle with sexually compulsive behaviors also experience symptoms such as cravings, tolerance, and withdrawal (S. Carnes, 2011; Kraus, Voon, \& Potenza, 2016).

\section{Codependency}

The concept of codependency first emerged in the 1960's and 1970's as a means of describing the behavior of wives of alcoholics (Cermak, 1991; Harkness, Swenson, MadsenHampton, \& Hale, 2001; Vogeler, 2017). The term, originally co-alcoholic, referred to a pattern of enabling, or "aiding and abetting an addicted person's behavior through over-zealous helping" (Harkness et al., 2001, p. 160; Vogeler, 2017). Over time, as alcoholism was incorporated into the more general categories of chemical abuse and dependence, co-alcoholism changed into coaddiction and eventually into co-dependence (Cermak, 1991; Vogeler, 2017). Now, more than 70 years after its initial introduction, codependency has become the preferred model of conceptualization for the symptoms and reactions experienced by partners of individuals with addictions (Ferree, 2002; Hentsch-Cowles \& Brock, 2013; King, 2003; Marks, Blore, Hine, \& Dear, 2012; Matheny, 1998; Milrad, 1999; Minwalla, 2012; Tripodi, 2006; Vogeler, 2017).

\section{Controversy Over Codependency}

Recently, research has called into question the applicability of the term codependence, with many wondering if the concept has become an outdated and inaccurate means of making sense of the relationship between partners and addicts (Panaghi, Ahmadabadi, Khosravi, 
Sadeghi, \& Madanipour, 2016). Shaef (as cited in Prest \& Protinsky, 1993) declared codependency to be an epidemic resulting from a codependent society, and Lindley and Giordano (1999) assert that the term codependency has become so broad that it has lost its "theoretical rigor and explanatory power. If codependency explains everything, then it really explains nothing" (p. 60). These arguments are gaining traction in the addiction community at large, and are becoming especially prevalent among researchers who are branching out from the field of traditional chemical dependency and addiction into the field of compulsive behaviors and addiction.

Although the term codependency was once reserved to describe the experience of close family members of alcoholics, it has become a broad-reaching term used to describe a generic, dysfunctional style of relating to others, not just the relationship between partners and addicts (Harkness et al., 2001; Lindley \& Giordano, 1999; Springer, Britt, \& Schlenker, 1998; Wells, Hill, Brack, Brack, \& Firestone, 2006). In light of this, Plant and Plant (2009) have argued that the concept of codependency, though popular in the United States, has become increasingly confused and complex and therefore difficult to apply in clinical practice (Vogeler, Fischer, Sudweeks, \& Skinner, 2018). Furthermore, notwithstanding the increasing complexity of the concept, codependency is often still preferred diagnostic model for partners of addicts. This sweeping diagnostic categorization also includes partners of individuals with sexual addiction, despite the growing body of evidence suggesting that the experiences of partners of sex addicts are qualitatively different from partners of individuals with substance addictions (Minwalla, 2012; Steffens \& Rennie, 2006; Vogeler et al., 2018). 


\section{The Experiences of Partners of Sex Addicts}

Several recent studies suggest that the experience of partners of sex addicts might better be conceptualized from a framework of trauma, rather than codependency (Carnes \& O'Connor, 2016; Steffens, 2005; Steffens \& Rennie, 2006; Vogeler et al., 2018). This seems especially true with regards to the discovery and/or disclosures of sexually compulsive and addictive behaviors. Steffens and Rennie (2006) explain that using a trauma model, "rather than conceptualizing [the partner's] symptomatic responses as arising from her own dysfunction and addiction, [the partner's] responses serve as a reaction to a stressor that is traumatic in nature, in predictable emotional, behavioral, and physiological ways" (p. 261). Additionally, Hentsch-Cowles and Brock (2013) described the trauma model by noting that it emphasizes "the betrayal, the shock, the PTSD symptoms, and the ultimate victimization of the partner, when the sexual addict's behaviors are discovered or finally acknowledged, with special underscoring that that partner committed no wrong in being victimized this way" (p. 328).

While research regarding the traumatic nature of infidelity has been prevalent over the last 20 years (see Glass \& Wright, 1997; Gordon \& Baucom, 1999; Gordon, Baucom, \& Snyder, 2004; Schneider \& Corley, 2002; Whisman \& Wagers, 2005), the traumatic nature of the discovery/disclosure of an intimate partner's sexual addiction or compulsive sexual behavior has been largely neglected. As a result, many professionals who work with individuals who have experienced discovery/disclosure may have relied on the traditional addiction/codependency model to conceptualize treatment. However, recent research suggests a trauma model may be more appropriate when conceptualizing symptoms and working with these individuals (Schneider, Weiss, \& Samenow, 2012; Steffens \& Rennie, 2006; Vogeler et al., 2018). 


\section{Defining Trauma}

One deterrent from utilizing a trauma model of conceptualization is the definition of trauma itself. According to Criterion A for Posttraumatic Stress Disorder (PTSD) in the $5^{\text {th }}$ edition of the Diagnostic and Statistical Manual of Mental Disorders (DSM-5), the traumatic, or precipitating, event(s) must involve "exposure to actual or threatened death, serious injury, or sexual violence" (American Psychiatric Association, 2013, p. 271). Giordano et al. (2016) further clarify that, under this definition, "individuals may [also] directly experience or witness the trauma, hear of a loved one's traumatic event, or repeatedly hear of or see trauma" (p. 56).

There are many who consider this definition of trauma to be too restrictive (Anders, Frazier, \& Frankfurt, 2011; Weathers \& Keane, 2007). Briere and Scott (2015) point out that earlier editions of the DSM included threats to psychological integrity as traumatic events; however, DSM-5 "does not consider events to be traumatic if they are merely highly upsetting but not life threatening... [therefore,] it undoubtedly underestimates the extent of actual trauma in the general population" (pp. 9-10). As such, Briere and Scott define an event as traumatic if it is "extremely upsetting, at least temporarily overwhelms the individual's internal resources, and produces lasting psychological symptoms" $(2015$, p. 10). Under this definition, the experiences of partners of sex addicts can therefore qualify as traumatic.

Non-life-threatening trauma. Several recent studies suggest that even when an event does not meet Criterion A, the event still has a traumatic effect, including symptoms of PTSD (Anders et al., 2011; Giordano et al., 2016; Steffens \& Rennie, 2006; Vogeler et al., 2018; Weathers \& Keane, 2007). For example, Anders et al. (2011) completed a study in which events that both met and did not meet Criterion A were compared, with both types of events resulting in symptoms of PTSD. Furthermore, events that did not meet Criterion A were generally 
associated with higher rates PTSD symptoms than Criterion A events (Anders et al., 2011; Vogeler, 2017). Steffens and Rennie (2006) found similar results, reporting that $69 \%$ of participants met all of the criteria for PTSD except for Criterion A. In addition, 50\% of the participants reported moderate to severe symptoms of PTSD (Steffens \& Rennie, 2006).

The work of van der Kolk and others addresses non-life-threatening trauma, asserting that, "women who are exposed to prolonged interpersonal violence consistently report a range of psychological sequelae that are not captured in the PTSD diagnostic criteria" (van der Kolk, Roth, Pelcovitz, Sunday, \& Spinazzola, 2005, p. 390). Captured under the term “complex trauma," this experience is described as "multiple, chronic and prolonged, developmentally adverse traumatic events, most often of an interpersonal nature....and early-life onset" (van der Kolk, 2005, p. 402). As compared to individuals who experience isolated traumatic events, those with a complex trauma history tend to experience developmental impairments in self-regulation and interpersonal functioning (Cook et al., 2017). These impairments, in turn, can lead to difficulty negotiating relationships with parents and caregivers, peers, and marital partners (van der Kolk et al., 2005).

In addition to complex trauma, other studies suggest that betrayal may be a core dimension of trauma, and that it may be possible to differentially predict symptoms of PTSD resulting from instances of betrayal and threat to life (Freyd \& Birrell, 2013; Gomez, Lewis, Noll, Smidt, \& Birrell, 2016; Kelley, Weathers, Mason, \& Pruneau, 2012; Platt \& Freyd, 2015). As such, there appears to be cause to acknowledge that symptoms of PTSD can result not only from an event with a perceived life threat, but also from an event involving a betrayal of a trusted relationship (Kelley et al., 2012). 
Betrayal trauma. According to Birrell and Freyd (2006), "[T]raumas that occur in the context of interpersonal relationships can be particularly detrimental because of the betrayal involved in the violation of basic assumptions of interpersonal and social relationships" (p. 50). The concept of betrayal trauma was first introduced by Freyd in 1991, and is generally defined as trauma that "occurs when the people or institutions we depend on for survival violate us in some way" (Freyd, 2003, para. 1). Freyd originally used the terms betrayal trauma and betrayal trauma theory in connection with childhood traumas, specifically childhood sexual abuse. However, in her later work, Freyd expanded her definition of betrayal trauma to include relational traumas that: (a) occur within the context of a current or ongoing relationship; and (b) that violate the bonds of the relationship (Birrell \& Freyd, 2006). Rather than being used exclusively in the context of childhood sexual abuse, betrayal trauma has now been associated with discrimination, workplace exploitation, institutional betrayal, and sexual infidelity (Freyd, 2013; Gomez et al., 2016; Smith \& Freyd, 2014). Under this expanded definition of betrayal trauma, betrayal associated with sexual or romantic infidelity, whether in vivo or online, can result in psychological trauma (Schneider et al., 2012).

Emotional responses to such betrayals can mirror what have previously been defined as codependent behaviors. These responses often include the following: feeling responsible for another's behavior; making excuses for another's behavior; avoiding confrontation because of fear of abandonment; and doubting attractiveness and self-worth (Schneider et al., 2012). As many standard psychological treatments either implicitly or explicitly focus on symptom reduction, this overlap of symptomatology between codependency and betrayal trauma can make it hard for clinicians to determine the most appropriate course of treatment for those who have experienced a traumatic betrayal (Birrell \& Freyd, 2006; Schneider et al., 2012). Therefore, 
continued research into the symptoms of PTSD associated with betrayal trauma - specifically in regards to partners of sex addicts - is essential in order to provide the best treatment possible for these individuals. 


\section{References}

American Psychiatric Association. (1987). Diagnostic and statistical manual of mental disorders (3rd ed., revised ed.). Washington, DC: Author.

American Psychiatric Association. (1994). Diagnostic and statistical manual of mental disorders (4th ed.). Washington, DC: Author.

American Psychiatric Association. (2000). Diagnostic and statistical manual of mental disorders (4th ed., Text Revision ed.). Washington, DC: Author.

American Psychiatric Association. (2013). Diagnostic and statistical manual of mental disorders (5th ed.). Arlington, VA: American Psychiatric Publishing.

Anders, S. L., Frazier, P. A., \& Frankfurt, S. B. (2011). Variations in Criterion A and PTSD rates in a community sample of women. Journal of Anxiety Disorders, 25(2), 176-184. doi:10.1016/j.janxdis.2010.08.018

Birrell, P. J., \& Freyd, J. J. (2006). Betrayal trauma. Journal of Trauma Practice, 5(1), 49-63. doi:10.1300/J189v05n01_04

Briere, J. N., \& Scott, C. (2015). Principles of trauma therapy: A guide to symptoms, evaluation, and treatment (DSM-5 Update) (2nd ed.). Thousand Oaks, CA: Sage Publications, Inc.

Carnes, P. (1983). Out of the shadows: Understanding sexual addiction. Minneapolis, MN: CompCare.

Carnes, S. (2011). What is sex addiction. In S. Carnes (Ed.), Mending a shattered heart: A guide for partners of sex addicts (pp. 7-24). Carefree, AZ: Gentle Path Press.

Carnes, S., \& O'Connor, S. (2016). Confirmatory analysis of the Partner Sexuality Survey. Sexual Addiction \& Compulsivity, 23(1), 141-153. doi:10.1080/10720162.2015.1039151

Cermak, T. L. (1991). Co-addiction as a disease. Psychiatric Annals, 21(5), 266-272. 
Cook, A., Spinazzola, J., Ford, J., Lanktree, C., Blaustein, M., Cloitre, M., . . van der Kolk, B. A. (2017). Complex trauma in children and adolescents. Psychiatric Annals, 35(5), 390398.

Ferree, M. C. (2002). Sexual addiction and co-addiction: Experiences among women of faith. Sexual Addiction \& Compulsivity, 9(4), 285-292. doi:1080/10720160290062374

Freyd, J. J. (1991). Memory repression, dissociative states, and other cognitive control processes involved in adult sequelae of childhood trauma. Paper presented at the Second Annual Conference on a Psychodynamics - Cognitive Science Interface, San Francisco, CA.

Freyd, J. J. (2003). What is a betrayal trauma? What is betrayal trauma theory? Retrieved from https://scholarsbank.uoregon.edu/xmlui/bitstream/handle/1794/65/defineBT.html?sequen $\mathrm{ce}=1$

Freyd, J. J. (2013). Preventing betrayal. Journal of Trauma \& Dissociation, 14(5), 495-500. doi:10.1080/15299732.2013.824945

Freyd, J. J., \& Birrell, P. (2013). Blind to betrayal: Why we fool ourselves we aren't being fooled. Hoboken, NJ: Wiley.

Giordano, A. L., Prosek, E. A., Stamman, J., Callahan, M. M., Loseu, S., Bevly, C. M., ... Chadwell, K. (2016). Addressing trauma in substance abuse treatment. Journal of Alcohol and Drug Education, 60(2), 55-71.

Glass, S. P., \& Wright, T. L. (1997). Reconstructing marriages after the trauma of infidelity. In W. K. Halford \& H. J. Markman (Eds.), Clinical handbook of marriage and couples interventions (pp. 471-507). Hoboken, NJ: John Wiley \& Sons Inc.

Gomez, J. M., Lewis, J. K., Noll, L. K., Smidt, A. M., \& Birrell, P. J. (2016). Shifting the focus: Nonpathologizing approaches to healing from betrayal trauma through an emphasis on 
relational care. Journal of Trauma and Dissociation, 17(2), 165-185. doi:10.1080/15299732.2016.1103104

Gordon, K. C., \& Baucom, D. H. (1999). A multitheoretical intervention for promoting recovery from extramarital affairs. Clinical Psychology Science and Practice, 6(4), 382-399.

Gordon, K. C., Baucom, D. H., \& Snyder, D. K. (2004). An integrative intervention for promoting recovery from extramarital affairs. Journal of Marital and Family Therapy, $30(2), 213-231$.

Grant, J. E., Potenza, M. N., Weinstein, A., \& Gorelick, D. A. (2010). Introduction to behavioral addictions. The American Journal of Drug and Alcohol Abuse, 36(5), 233-241. doi:10.3109/00952990.2010.491884

Harkness, D., Swenson, M., Madsen-Hampton, K., \& Hale, R. (2001). The development, reliability, and validity of a clinical rating scale for codependency. Journal of Psychoactive Drugs, 33(2), 159-171.

Hentsch-Cowles, G., \& Brock, L. J. (2013). A systemic review of the literature on the role of the partner of the sex dddict, treatment models, and a call for research for systems theory model in treating the partner. Sexual Addiction \& Compulsivity, 20(4), 323-335. doi:10.1080/10720162.2013.845864

Kafka, M. P. (2010). Hypersexual disorder: A proposed diagnosis for DSM-V. Archives of Sexual Behavior, 39(2), 377-400. doi:10.1007/s10508-009-9574-7

Kafka, M. P. (2013). The development and evolution of the criteria for a newly proposed diagnosis for DSM-5: Hypersexual disorder. Sexual Addiction \& Compulsivity, 20(1-2), 19-26. doi:10.1080/10720162.2013.768127 
Kelley, L. P., Weathers, F. W., Mason, E. A., \& Pruneau, G. M. (2012). Association of life threat and betrayal with posttraumatic stress disorder symptom severity. Journal of Traumatic Stress, 25(4), 408-415. doi:10.1002/jts.21727

King, S. (2003). The impact of compulsive sexual behaviors on clergy marriages: Perspectives and concerns of the pastor's wife. Sexual Addiction \& Compulsivity, 10(2-3), 193-199. doi:1080/107201603902306307

Kraus, S. W., Voon, V., \& Potenza, M. N. (2016). Should compulsive sexual behavior be considered an addiction? Addiction, 111(12), 2097-2106. doi:10.1111/add.13297

Lindley, N. R., \& Giordano, P. J. (1999). Codependency predictors and psychometric issues. Journal of Clinical Psychology, 55(1), 59-64.

Marks, A. D. G., Blore, R. L., Hine, D. W., \& Dear, G. E. (2012). Development and validation of a revised measure of codependency. Australian Journal of Psychology, 64(3), 119-127. doi:10.1111/j.1742-9536.2011.00034.X

Martin, P. R., \& Petry, N. M. (2005). Are non-substance-related addictions really addictions? The American Journal on Addiction, 14(1), 1-7. doi:10.1080/10550490590899808

Matheny, J. H. (1998). Strategies for assessment and early treatment with sexually addicted families. Sexual Addiction \& Compulsivity, 5(1), 27-48.

Milrad, R. (1999). Coaddictive recovery: Early recovery issues for spouses of sex addicts. Sexual Addiction \& Compulsivity, 6(2), 125-136.

Minwalla, O. (2012, Jul 23). Partners of sex addicts need treatment for trauma. Retrieved from http://nationalpsychologist.com/2012/07/partners-of-sex-addicts-need-treatment-for-trau ma 
Morgan, J., J. P. (1991). What is codependency? Journal of Clinical Psychology, 47(5), 720729.

Panaghi, L., Ahmadabadi, Z., Khosravi, N., Sadeghi, M. S., \& Madanipour, A. (2016). Living with addicted men and codependency: The moderating effect of personality traits. Addiction and Health, 8(2), 98-106.

Plant, M., \& Plant, M. (2009). Sex addiction: A comparison with dependence on psychoactive drugs. Journal of Substance Use, 8(4), 260-266. doi:10.1080/14659890310001636125

Platt, M. G., \& Freyd, J. J. (2015). Betray my trust, shame on me: Shame, dissociation, fear, and betrayal trauma. Psychological Trauma: Theory, Research, Practice, and Policy, 7(4), 398-404. doi:10.1037/tra0000022

Prest, L. A., \& Protinsky, H. (1993). Family systems theory: A unifying framework for codependence. American Journal of Family Therapy, 21(4), 352-360.

Reid, R. C., Carpenter, B. N., Hook, J. N., Garos, S., Manning, J. C., Gilliland, R., ... Fong, T. (2012). Report of findings in a DSM-5 field trial for hypersexual disorder. Journal of Sexual Medicine, 9(11), 2868-2877. doi:10.1111/j.1743-6109.2012.02936.x

Schneider, J. P., \& Corley, M. D. (2002). Disclosure of extramarital sexual activities by persons with addictive or compulsive sexual disorders: Results of a study and implications for therapists. In P. Carnes \& K. Adams (Eds.), Clinical management of sex addiction (pp. 137-162). New York, NY: Brunner-Routledge Publishers.

Schneider, J. P., Weiss, R., \& Samenow, C. (2012). Is it really cheating? Understanding the emotional reactions and clinical rreatment of spouses and partners affected by cybersex infidelity. Sexual Addiction \& Compulsivity, 19(1-2), 123-139.

doi:10.1080/10720162.2012.658344 
Smith, C. P., \& Freyd, J. J. (2014). Institutional betrayal. American Psychologist, 69(6), 575587. doi:10.1037/a0037564

Springer, C. A., Britt, T. W., \& Schlenker, B. R. (1998). Codependency: Clarifying the construct. Journal of Mental Health Counseling, 20(2), 141-158.

Steffens, B. A. (2005). The effects of disclosure on wives of sexual addicts (Doctoral dissertation). Retrieved from https://search.proquest.com/docview/305353623?accountid=4488

Steffens, B. A., \& Rennie, R. L. (2006). The traumatic nature of disclosure for wives of sexual addicts. Sexual Addiction \& Compulsivity, 13(2-3), 247-267. doi:10.1080/10720160600870802

Tripodi, C. (2006). Long term treatment of partners of sex addicts: A multi-phase approach. Sexual Addiction \& Compulsivity, 13(2-3), 269-288. doi:10.1080/10720160600870810 van der Kolk, B. A. (2005). Developmental Trauma Disorder: Toward a rational diagnosis for children with complex trauma histories. Psychology Module, 35(5), 401-408.

van der Kolk, B. A., Roth, S., Pelcovitz, D., Sunday, S., \& Spinazzola, J. (2005). Disorders of extreme stress: The empirical foundation of a complex adaptation to trauma. Journal of Traumatic Stress, 18(5), 389-399. doi:10.1002/jts.20047

Vogeler, H. A. (2017). An examination of the factor structure of the Trauma Inventory for Partners of Sex Addicts (TIPSA) (Doctoral dissertation). Retrieved from https://scholarsarchive.byu.edu/cgi/viewcontent.cgi?article $=7654 \&$ context $=$ etd Vogeler, H. A., Fischer, L., Sudweeks, R. R., \& Skinner, K. B. (2018). An examination of the factor structure of the Trauma Inventory for Partners of Sex Addicts (TIPSA). Sexual Addiction \& Compulsivity, 25(1), 46-61. doi:10.1080/10720162.2018.1452086 
Weathers, F. W., \& Keane, T. M. (2007). The Criterion A problem revisited: Controversies and challenges in defining and measuring psychological trauma. Journal of Traumatic Stress, 20(2), 107-121. doi:10.1002/jts.20210

Wells, M. C., Hill, M. B., Brack, G., Brack, C. J., \& Firestone, E. E. (2006). Codependency's relationship to defining characteristics in college students. Journal of College Student Psychotherapy, 20(4), 71-84. doi:10.1300/J035v20n04_07

Whisman, M. A., \& Wagers, T. P. (2005). Assessing relationship betrayals. Journal of Clinical Psychology, 61(11), 1383-1391. doi:10.1002/jclp.20188 


\section{APPENDIX B}

\section{Institutional Review Board}

\section{Letter of Approval}

Bvv

Institutional ReView BoARD

For Human Subjects

\section{Memorandum}

To: Professor Lane Fischer

Department: CP\&SE

College: EDUC

From: Sandee Aina, MPA, IRB Administrator; Bob Ridge, PhD, IRB Chair

Date: March 4, 2019

IRB\#: E19038

Title: "Assessing the Validity of the Trauma Inventory for Partners of Sex Addicts (TIPSA)"

Brigham Young University's IRB has approved the research study referenced in the subject heading as exempt level, category 2. The approval period is from March 4, 2019 to March 3, 2020. Please reference your assigned IRB identification number in any correspondence with the IRB. Continued approval is conditional upon your compliance with the following requirements:

1. A copy of the informed consent statement is attached. No other consent statement should be used. Each research subject must be provided with a copy or a way to access the consent statement.

2. Any modifications to the approved protocol must be submitted, reviewed, and approved by the IRB before modifications are incorporated in the study.

3. All recruiting tools must be submitted and approved by the IRB prior to use.

4. In addition, serious adverse events must be reported to the IRB immediately, with a written report by the PI within 24 hours of the PI's becoming aware of the event. Serious adverse events are (1) death of a research participant; or (2) serious injury to a research participant.

5. All other non-serious unanticipated problems should be reported to the IRB within 2 weeks of the first awareness of the problem by the PI. Prompt reporting is important, as unanticipated problems often require some modification of study procedures, protocols, and/or informed consent processes. Such modifications require the review and approval of the IRB.

6. A few months before the expiration date, you will receive a continuing review form. There will be two reminders. Please complete the form in a timely manner to ensure that there is no lapse in the study approval. 


\section{Implied Consent}

This study is being conducted by Heidi Vogeler, $\mathrm{PhD}$ and Lane Fischer, $\mathrm{PhD}$ from the Counseling Psychology Department at Brigham Young University (BYU), in conjunction with Kevin Skinner, PhD from Addo Recovery. We are interested in finding out about the experiences of partners of sex addicts.

The following survey will likely take approximately 20 - 30 minutes of your time, and your answers will be used for research purposes. Your participation will be anonymous and you will not be contacted again in the future. You will not be paid for completing this survey, and you must be at least 18 years old to participate.

Completing the survey is completely voluntary. Sometimes questions in surveys like this one can trigger emotional discomfort. Examples of these types of questions include:

- While you were growing up, during the first 18 years of life, did anyone at least 5 years older than you or an adult, ever touch you sexually?

- Has your partner physically hurt you while acting out his/her sexual fantasies?

If while taking this survey you experience any emotional discomfort and you feel like you need help dealing with the discomfort, please contact a professional therapist or counselor as soon as possible.

You do not have to participate in this study if you do not want to. And, you may skip any question that you do not want to answer for any reason. If you have any questions about your rights as a research participant you may contact the IRB Administrator at A-285 ASB, Brigham Young University, Provo, UT 84602; irb@byu.edu; (801) 422-1461. The IRB is a group of people who review research studies to protect the rights and welfare of research participants.

The completion of this survey implies your consent to participate. Completion of this survey also implies that you are $\mathbf{1 8}$ years of age or older. If you choose to participate, please click NEXT to continue to the survey.

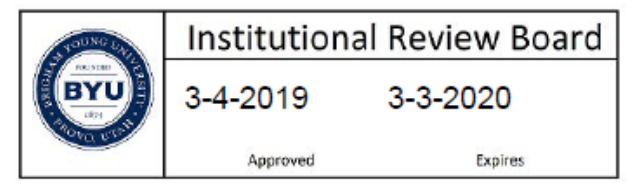




\section{APPENDIX C}

\section{Instruments}

\section{Trauma Inventory for Partners of Sex Addicts (TIPSA)}

\begin{tabular}{|c|c|c|c|c|c|}
\hline $\begin{array}{c}\text { CRITERION A } \\
\text { Since discovering your partner's sexual behaviors, how often: }\end{array}$ & 产 & 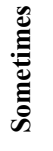 & 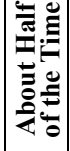 & 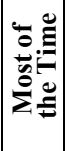 & \\
\hline 1. Has your partner physically hurt you while acting out his/her sexual fantasies & 0 & 1 & 2 & 3 & \\
\hline $\begin{array}{l}\text { 2. Do you worry that you that you might contract a sexually transmitted disease because of } \\
\text { your partner's sexual behaviors }\end{array}$ & 0 & 1 & 2 & 3 & 4 \\
\hline 3. Do you feel violated by your partner's sexual behaviors & 0 & 1 & 2 & 3 & 4 \\
\hline 4. Do you experience fear being around your partner & 0 & 1 & 2 & 3 & 4 \\
\hline 5. Have you been pressured to perform sexually in ways & 0 & 1 & 2 & 3 & 4 \\
\hline 6. Has your partner hurt, hit, or threatened you & 0 & 1 & 2 & 3 & 4 \\
\hline 7. Has your partner forced you to have sex with him/her & 0 & 1 & 2 & 3 & 4 \\
\hline 8. Have you been physically harmed through sex acts with your partner & 0 & 1 & 2 & 3 & 4 \\
\hline 9. Have you been injured by your partner during sex and as a result sought med & 0 & 1 & 2 & 3 & 4 \\
\hline $\begin{array}{c}\text { CRITERION B } \\
\text { Since discovering your partner's sexual behaviors, how often have you: }\end{array}$ & 离 & 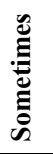 & 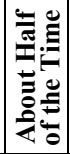 & 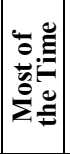 & \\
\hline 10. Looked at you & 0 & 1 & 2 & 3 & 4 \\
\hline 11. Had painful memories that remind you of your partner's sexual behaviors & 0 & 1 & 2 & 3 & 4 \\
\hline 12. Had disturbing dreams that remind you of your partner's sexual behaviors & 0 & 1 & 2 & 3 & 4 \\
\hline $\begin{array}{l}\text { 13. Questioned whether your partner is thinking about you or things } \mathrm{s} / \text { he has done (when } \\
\text { you are close or sexually intimate) }\end{array}$ & 0 & 1 & 2 & 3 & 4 \\
\hline 14. Had episodes where you feel like you are reliving the discovery over and over again & 0 & 1 & 2 & 3 & 4 \\
\hline $\begin{array}{l}\text { 15. Found media (like movies, T.V., Internet) difficult to watch because it reminds } \\
\text { what your partner has done }\end{array}$ & 0 & 1 & 2 & 3 & 4 \\
\hline $\begin{array}{l}\text { 16. Found it difficult to be in public places with your partner because you have become } \\
\text { sensitive to what s/he is looking at }\end{array}$ & 0 & 1 & 2 & 3 & 4 \\
\hline 17. Become anxious when you see sexually suggestive images & 0 & 1 & 2 & 3 & 4 \\
\hline $\begin{array}{l}\text { 18. Become physically ill (i.e. nauseous, head-aches, panic atta } \\
\text { exposed to things that remind you of what your partner has }\end{array}$ & 0 & 1 & 2 & 3 & 4 \\
\hline 19. Struggled to think of other things besides your partner's sexual behaviors & 0 & 1 & 2 & 3 & 4 \\
\hline $\begin{array}{c}\text { CRITERION C } \\
\text { Since discovering your partner's sexual behaviors, how often have you: }\end{array}$ & 产 & $\stackrel{\mathscr{E}}{\mathscr{E}}$ & 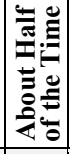 & 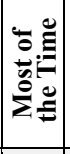 & \\
\hline $\begin{array}{l}\text { 20. Attempted to avoid memories, thoughts, or feelings related to your partner's sexual } \\
\text { behaviors }\end{array}$ & 0 & 1 & 2 & 3 & 4 \\
\hline $\begin{array}{l}\text { 21. Engaged in behaviors that distract you from thinking about your partner's sexual } \\
\text { behavior (i.e. excessive reading, sleeping, eating, drinking) }\end{array}$ & 0 & 1 & 2 & 3 & 4 \\
\hline 22. Avoided sexual interaction with your partner since discovering his/her sexual behavior & 0 & 1 & 2 & 3 & 4 \\
\hline 23. Found it difficult to participate in things that you previously enjoyed & 0 & 1 & 2 & 3 & 4 \\
\hline
\end{tabular}




\begin{tabular}{|c|c|c|c|c|c|}
\hline 24. Avoided people, places, or activities that you used to enjoy & 0 & 1 & 2 & 3 & 4 \\
\hline 25. Had trouble remembering important parts of the experience & 0 & 1 & 2 & 3 & 4 \\
\hline $\begin{array}{l}\text { CRITERION D } \\
\text { Since discovering your partner's sexual behaviors, how often have you: }\end{array}$ & $\stackrel{\grave{0}}{\grave{0}}$ & 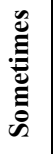 & 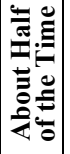 & 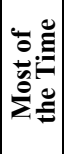 & $\frac{\overbrace{i}^{2}}{4}$ \\
\hline 26. Felt like your partner acts out because you are not good enough & 0 & 1 & 2 & 3 & 4 \\
\hline 27. Felt like it is your fault that your partner sexually acted out & 0 & 1 & 2 & 3 & 4 \\
\hline 28. Felt like it is hard to trust anyone & 0 & 1 & 2 & 3 & 4 \\
\hline 29. Felt ashamed because of your partner's sexual behaviors & 0 & 1 & 2 & 3 & 4 \\
\hline 30. Held back from people who used to be close to you & 0 & 1 & 2 & 3 & 4 \\
\hline $\begin{array}{l}\text { 31. Enjoyed doing things you enjoyed doing before discovering your partner's sexual } \\
\text { behavior }\end{array}$ & 0 & 1 & 2 & 3 & 4 \\
\hline 32. Felt like you are a bad person because of what your partner has done & 0 & 1 & 2 & 3 & 4 \\
\hline 33. Felt like you don't belong anymore due to your partner's sexual behaviors & 0 & 1 & 2 & 3 & 4 \\
\hline 34. Felt like you are different than everyone else & 0 & 1 & 2 & 3 & 4 \\
\hline 35. Questioned whether people are safe to be around & 0 & 1 & 2 & 3 & 4 \\
\hline 36. Felt depressed as a result of your partner's sexual behaviors & 0 & 1 & 2 & 3 & 4 \\
\hline 37. Felt stupid for not discovering your partner's sexual behaviors earlier than you did & 0 & 1 & 2 & 3 & 4 \\
\hline 38. Felt like you are unlovable & 0 & 1 & 2 & 3 & 4 \\
\hline $\begin{array}{c}\text { CRITERION E } \\
\text { Since discovering your partner's sexual behaviors, how often do you: }\end{array}$ & $\stackrel{\grave{D}}{\grave{\partial}}$ & 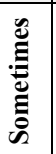 & 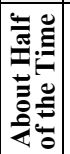 & 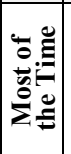 & $\frac{n}{e_{\pi}^{2}}$ \\
\hline 39. Struggled to fall asleep or stay asleep & 0 & 1 & 2 & 3 & 4 \\
\hline 40. Become angry when talking to your partner & 0 & 1 & 2 & 3 & 4 \\
\hline 41. Felt emotionally on edge since discovering your partner's sexual behaviors & 0 & 1 & 2 & 3 & 4 \\
\hline 42. Found it harder to concentrate on important things than it was before & 0 & 1 & 2 & 3 & 4 \\
\hline 43. Become easily distracted & 0 & 1 & 2 & 3 & 4 \\
\hline 44. Found that you are critical of your partner & 0 & 1 & 2 & 3 & 4 \\
\hline 45. Inflicted physical pain/harm on yourself & 0 & 1 & 2 & 3 & 4 \\
\hline 46. Monitored your partner's sexual behaviors & 0 & 1 & 2 & 3 & 4 \\
\hline 47. Felt jumpy or get easily startled & 0 & 1 & 2 & 3 & 4 \\
\hline 48. Tried to read your partner's emotions & 0 & 1 & 2 & 3 & 4 \\
\hline 49. Checked up on what your partner is doing & 0 & 1 & 2 & 3 & 4 \\
\hline 50. Felt anxious & 0 & 1 & 2 & 3 & 4 \\
\hline 51. Had thoughts about suicide & 0 & 1 & 2 & 3 & 4 \\
\hline
\end{tabular}




\section{PTSD Checklist for DSM-5 (PCL-5)}

\begin{tabular}{|c|c|c|c|c|c|}
\hline $\begin{array}{l}\text { Instructions: Below is a list of problems that people sometimes have in response } \\
\text { to a very stressful experience (in this case, the discovery of your partner's } \\
\text { behaviors). Please read each problem carefully and then select one of the options } \\
\text { to the right to indicate how much you have been bothered by that problem in the } \\
\text { past month. } \\
\text { In the past month, how much were you bothered by: }\end{array}$ & $\frac{\bar{\sigma}}{\stackrel{5}{\sigma}}$ & 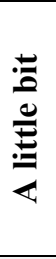 & 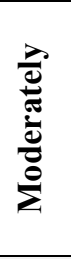 & 竞 & 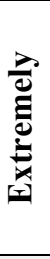 \\
\hline 1. Repeated, disturbing, and unwanted memories of the stressful experience? & 0 & 1 & 2 & 3 & 4 \\
\hline 2. Repeated, disturbing dreams of the stressful experience? & 0 & 1 & 2 & 3 & 4 \\
\hline $\begin{array}{l}\text { 3. Suddenly feeling or acting as if the stressful experience were actually } \\
\text { happening again (as if you were actually back there reliving it)? }\end{array}$ & 0 & 1 & 2 & 3 & 4 \\
\hline $\begin{array}{l}\text { 4. Feeling very upset when something reminded you of the stressful } \\
\text { experience? }\end{array}$ & 0 & 1 & 2 & 3 & 4 \\
\hline $\begin{array}{l}\text { 5. Having strong physical reactions when something reminded you of the } \\
\text { stressful experience (for example, heart pounding, trouble breathing, } \\
\text { sweating)? }\end{array}$ & 0 & 1 & 2 & 3 & 4 \\
\hline $\begin{array}{l}\text { 6. Avoiding memories, thoughts, or feelings related to the stressful } \\
\text { experience? }\end{array}$ & 0 & 1 & 2 & 3 & 4 \\
\hline $\begin{array}{l}\text { 7. Avoiding external reminders of the stressful experience (for example, } \\
\text { people, places, conversations, activities, objects, or situations)? }\end{array}$ & 0 & 1 & 2 & 3 & 4 \\
\hline 8. Trouble remembering important parts of the stressful experience? & 0 & 1 & 2 & 3 & 4 \\
\hline $\begin{array}{l}\text { 9. Having strong negative beliefs about yourself, other people, or the world } \\
\text { (for example, having thoughts such as: I am bad, there is something seriously } \\
\text { wrong with me, no one can be trusted, the world is completely dangerous)? }\end{array}$ & 0 & 1 & 2 & 3 & 4 \\
\hline $\begin{array}{l}\text { 10. Blaming yourself or someone else for the stressful experience or what } \\
\text { happened after it? }\end{array}$ & 0 & 1 & 2 & 3 & 4 \\
\hline $\begin{array}{l}\text { 11. Having strong negative feelings such as fear, horror, anger, guilt, or } \\
\text { shame? }\end{array}$ & 0 & 1 & 2 & 3 & 4 \\
\hline 12. Loss of interest in activities that you used to enjoy? & 0 & 1 & 2 & 3 & 4 \\
\hline 13. Feeling distant or cut off from other people? & 0 & 1 & 2 & 3 & 4 \\
\hline $\begin{array}{l}\text { 14. Trouble experiencing positive feelings (for example, being unable to feel } \\
\text { happiness or have loving feelings for people close to you)? }\end{array}$ & 0 & 1 & 2 & 3 & 4 \\
\hline 15. Irritable behavior, angry outbursts, or acting aggressively? & 0 & 1 & 2 & 3 & 4 \\
\hline 16. Taking too many risks or doing things that could cause you harm? & 0 & 1 & 2 & 3 & 4 \\
\hline 17. Being "superalert" or watchful or on guard? & 0 & 1 & 2 & 3 & 4 \\
\hline 18. Feeling jumpy or easily startled? & 0 & 1 & 2 & 3 & 4 \\
\hline 19. Having difficulty concentrating? & 0 & 1 & 2 & 3 & 4 \\
\hline 20. Trouble falling or staying asleep? & 0 & 1 & 2 & 3 & 4 \\
\hline
\end{tabular}

Cluster B (items 1-5), Cluster C (items 6-7), Cluster D (items 8-14), and Cluster E (items 15-20)

A provisional PTSD diagnosis can be made by treating each item rated as 2 = "Moderately" or higher as a symptom endorsed, then following the DSM-5 diagnostic rule which requires at least: $1 \mathrm{~B}$ item (questions 1-5), $1 \mathrm{C}$ item (questions 6-7), 2 D items (questions 8-14), 2 E items (questions 15-20) 


\section{Adverse Childhood Experience (ACE) Module}

\section{\begin{tabular}{|l|l|} 
While you were growing up, during your first 18 years of life: & Yes $=1$
\end{tabular}

1) Did you live with anyone who was depressed, mentally ill, or suicidal?

2) Did you live with anyone who was a problem drinker or alcoholic?

3) Did you live with anyone who used illegal street drugs or who abused prescription medications?

4) Did you live with anyone who served time or was sentenced to serve time in a prison, jail, or other correctional facility?

5) Were your parents separated or divorced?

6) Did your parents or adults in your home ever slap, hit, kick, punch or beat each other up?

7) Before age 18 , did a parent or adult in your home ever hit, beat, kick, or physically hurt you in any way? Do not include spanking.

8) Did a parent or adult in your home ever swear at you, insult you, or put you down?

9) Did anyone at least 5 years older than you or an adult, ever touch you sexually?

10) Did anyone at least 5 years older than you or an adult, try to make you touch sexually?

11) Did anyone at least 5 years older than you or an adult, force you to have sex?

Now add up your "Yes" answers:

This is your ACE Score.

Reproduced and modified from: https://www.cdc.gov/violenceprevention/acestudy/pdf/BRFSS_Adverse_Module.pdf 


\section{Benevolent Childhood Experiences (BCE) Questionnaire}

\begin{tabular}{|c|c|}
\hline While you were growing up, during your first 18 years of life: & $\begin{array}{l}\text { Yes }=1 \\
\text { No }=0\end{array}$ \\
\hline 1) Did you have at least one caregiver with whom you felt safe? & \\
\hline 2) Did you have at least one good friend? & \\
\hline 3) Did you have beliefs that gave you comfort? & \\
\hline 4) Did you like school? & \\
\hline 5) Did you have at least one teacher who cared about you? & \\
\hline 6) Did you have good neighbors? & \\
\hline $\begin{array}{l}\text { 7) Was there an adult (not a parent/caregiver, or the person from \#1) who could provide you } \\
\text { with support or advice? }\end{array}$ & \\
\hline 8) Did you have opportunities to have a good time? & \\
\hline 9) Did you like yourself or feel comfortable with yourself? & \\
\hline 10) Did you have a predictable home routine, like regular meals and a regular bedtime? & \\
\hline
\end{tabular}

Now add up your "Yes" answers:

This is your BCE Score.

Reproduced from:

Narayan, A. J., Rivera, L. M., Bernstein, R. E., Harris, W. W., \& Lieberman, A. F. (2018). Positive childhood experiences predict less psychopathology and stress in pregnant women with childhood adversity: A pilot study of the benevolent childhood experiences (BCEs) scale. Child Abuse \& Neglect, 78, 19-30. 


\section{Composite Codependency Scale (CCS)}

\begin{tabular}{|c|c|c|c|c|c|}
\hline $\begin{array}{l}\text { Please indicate how strongly you agree with the following } \\
\text { statements: }\end{array}$ & 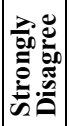 & 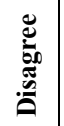 & $\frac{\bar{E}}{\overline{\bar{E}}}$ & 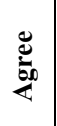 & \\
\hline $\begin{array}{l}\text { I. I try to control events and people through helplessness, guilt, coercion, threats, advice- } \\
\text { giving, manipulation, or domination }\end{array}$ & 0 & 1 & 2 & 3 & 4 \\
\hline 2. I become afraid to let other people be who they are and allow events to happen naturally & 0 & 1 & 2 & 3 & 4 \\
\hline 3. I try to control events and how other people should behave & 0 & 1 & 2 & 3 & 4 \\
\hline 4. I feel compelled or forced to help people solve their problems (i.e., offering advice) & 0 & 1 & 2 & 3 & 4 \\
\hline 5. I feel that without my effort and attention, everything would fall apart & 0 & 1 & 2 & 3 & 4 \\
\hline 6. My mood is fairly stable and unaffected by the problems and moods of those close to me & 0 & 1 & 2 & 3 & 4 \\
\hline 7. I live too much by other people's standards & 0 & 1 & 2 & 3 & 4 \\
\hline 8. I always put the needs of my family before my own needs & 0 & 1 & 2 & 3 & 4 \\
\hline 9. It is my responsibility to devote my energies to helping loved ones solve their problems & 0 & 1 & 2 & 3 & 4 \\
\hline 10. No matter what happens the family always comes first & 0 & 1 & 2 & 3 & 4 \\
\hline 11. I often put the needs of others ahead of my own & 0 & 1 & 2 & 3 & 4 \\
\hline 12. What I feel isn't important as long as those I love are okay & 0 & 1 & 2 & 3 & 4 \\
\hline 13. Because it is selfish, I cannot put my own needs before the 1 & 0 & 1 & 2 & 3 & 4 \\
\hline 14. Feelings often build up inside me that I do not express & 0 & 1 & 2 & 3 & 4 \\
\hline 15. I keep my emotions under tight control & 0 & 1 & 2 & 3 & 4 \\
\hline 16. I keep my feelings to myself and put up a good front & 0 & 1 & 2 & 3 & 4 \\
\hline 17. It makes me uncomfortable to share my feelings with others & 0 & 1 & 2 & 3 & 4 \\
\hline 18. I am very open with others about my feelings, no matter what they are & 0 & 1 & 2 & 3 & 4 \\
\hline 19. I push painful thoughts and feelings out of my awareness & 0 & 1 & 2 & 3 & 4 \\
\hline
\end{tabular}

Reproduced from: Marks, A. D. G., Blore, R. L., Hine, D. W., \& Dear, G. E. (2012). Development and validation of a revised measure of codependency. Australian Journal of Psychology, 64(3), 119-127. 